Dissertação apresentada como requisito parcial para obtenção do grau de Mestre pelo Programa de PósGraduação em Engenharia Elétrica da PUC-Rio.

Orientador: Prof: Jean Pierre von der Weid 


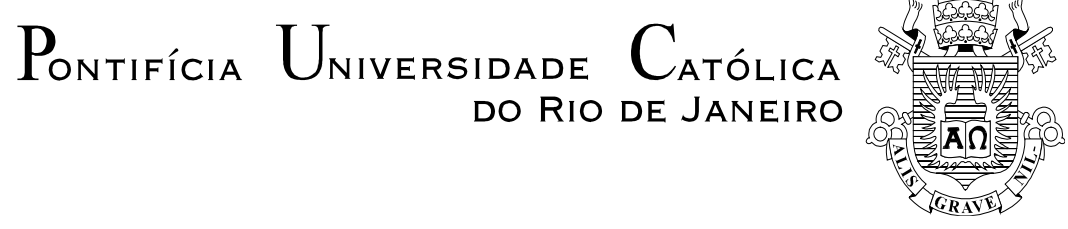

Andy Alvarez Arellano

\section{Transmissão e recepção de dados em EHF}

Dissertação apresentada como requisito parcial para obtenção do grau de Mestre pelo Programa de Pós-Graduação em Engenharia Elétrica da PUC-Rio. Aprovada pela Comissão Examinadora abaixo assinada.

Prof. Jean Pierre von der Weid Orientador Centro de Estudos em Telecomunicações - PUC-Rio

Prof. Ricardo Marques Ribeiro UFF

Prof. Andrew Henry Cordes

Centro de Estudos em Telecomunicações - PUC-Rio

Prof. Luis Ernesto Ynoquio Herrera Centro de Estudos em Telecomunicações - PUC-Rio

Prof. Márcio da Silveira Carvalho Coordenador Setorial do Centro Técnico Científico - PUC-Rio 
Todos os direitos reservados. É proibida a reprodução total ou parcial do trabalho sem autorização da universidade, do autor e do orientador.

Andy Alvarez Arellano

Gradou-se em Engenharia de Telecomunições pela universid Tecnológica del Perú - Lima - Perú 2012

Ficha Catalográfica

Alvarez Arellano, Andy

Transmissão e recepção de dados em EHF / Andy Alvarez Arellano; orientador: Jean Pierre Von der Weid. 2017

65 f. : il. (color.) ; $30 \mathrm{~cm}$

Dissertação (mestrado)-Pontifícia Universidade Católica do Rio de Janeiro, Departamento de Engenharia Elétrica, 2017.

Inclui referências bibliográficas.

1. Engenharia elétrica - Teses. 2. EHF (Extremely High Frequency) 3. QPSK (Quadrature phase-shift keying). 4. EVM (Error Vetor Magnitude). I. Weid, Jean Pierre Von der. II. Pontifícia Universidade Católica do Rio de Janeiro. Departamento de Engenharia Elétrica. III. Título. 


\section{Agradecimentos}

Gostaria de agradecer a meu orientador Jean Pierre von der Weid e Andrew Cordes pelos ensinamentos compartilhados, os conselhos e a confiança que eles me deram neste trabalho.

A meus pais Mauro Alvarez e Julia Arellano,e a meus irmãos Danny Alvarez e Michael Alvarez pelo apoio em estes anos que estive fora de Perú para poder obter mais um logro em minha vida.

A meus amigos Lisseth e Luis Talavera que sempre foram mais que amigos durante tudo este tempo em Brasil.

A meus amigos Carlos, Marcelo e Teddy com quem compartilhei muitos momentos agradáveis nestes dois anos, como também a Luis Ynoquio e Diego Villafani que me guiaram em toda a dissertação e ajudaram com minhas dúvidas.

A CAPES, CNPq e à PUC, pelo acolhimento e apoio no mestrado.

Finalmente a todos meus amigos da PUC e do Perú que fizeram esta experiência muito agradável. 
Resumo

Alvarez Arellano. Andy; Von der Weid, Jean Pierre. Transmissão e recepção de dados em EHF. Rio de Janeiro, 2017. 65p. Dissertação de Mestrado - Departamento de Engenharia Elétrica, Pontifícia Universidade Católica do Rio de Janeiro.

Nos últimos anos, as bandas de frequências nas comunicações sem fio estão começando a saturar devido ao incremento do tráfego e o aumento dos usuários, é devido a isso que, é necessário estudar as bandas de frequências que não estão sendo utilizadas nas áreas das comunicações como a banda milimétrica e sub-milimétrica. A transmissão de dados na banda EHF o banda milimétrica constitui uma possível solução para conseguir transmitir maiores quantidades de informação a altas velocidades de transmissão aliviando as bandas de frequências atuais. Neste trabalho se estuda a transmissão de dados em frequências de 100, 200, 300 e 400 GHz, empregando a modulação Quadrature Phase-Shift Keying (QPSK) mediante uma arquitetura baseada no batimento de dois lasers, cujas frequências são combinadas em um Beam Splitter, para que a corrente resultante da soma dos campos elétricos dos dois lasers seja convertida em um sinal de alta frequência por meio de uma antena fotocondutora. O batimento dos dois lasers, com diferentes comprimentos de onda e com a mesma potência, ao interagir com uma antena fotocondutora dá como resultado uma frequência na ordem de Gigahertz. No experimento utilizaram-se dois tipos de diodos receptores, um de banda larga $(<4$ $\mathrm{GHz})$ e outro de banda estreita $(<1 \mathrm{MHz})$. As duas antenas foram testadas em diferentes distâncias e com diferentes frequências de portadora para verificar qual delas tinha o melhor desempenho na banda EHF para poder realizar a transmissão de dados.

\section{Palavras-chave}

EHF (Extremely High Frequency); QPSK (Quadrature phase-shift keying) EVM (Error Vector Magnitude). 


\section{Abstract}

Alvarez Arellano .Andy; Von der Wid, Jean Pierre (Advisor). Transmission and reception of data in EHF. Rio de Janeiro, 2017. 65p. Dissertação de Mestrado - Departamento de Engenharia Elétrica, Pontifícia Universidade Católica do Rio de Janeiro.

In recent years, the frequency bands in wireless communications are beginning to saturate due to the increase of traffic and the increase of users, and it for that reason that is necessary to study the frequency bands that are not begin used in the communication areas like millimeter and sub-millimeters bands. Data transmission in the EHF band is a possible solution to be able to transmit large amounts of information at high transmission speeds, alleviating current frequency bands. In this work, the transmission of data in frequencies of 100, 200, 300 and 400 Gigahertz is studied, using Quadrature phase-shift keying (QPSK) modulation with an architecture based on the beat of two lasers, whos frequencies are combined by means of Beam Splitter, so that result of the electric fields of two lasers is converted into a high frequency signal with the aid of a photoconductor antenna. The.beating of the two lasers, with different wavelengths and with the same power, when interacting with a photoconductor antenna results in a frequency in the order of Gigahertz. In the experiment, two types of receiver diodes were used, one Broadband $(<4 \mathrm{GHz})$ and the other of narrowband $(<1 \mathrm{MHz})$. The two antennas were tested at different distances and with different carrier frequencies to verify which one had the best performance in the EHF band in order to perform the data transmission.

\section{Keywords}

EHF (Extremely High Frequency); QPSK (Quadrature phase-shift keying) EVM (Error Vector Magnitude) 


\section{Sumário}

1 Introdução 13

$\begin{array}{lll}1.1 & \text { Descrição do problema } & 15\end{array}$

1.2 Estado da Arte 15

$\begin{array}{lll}1.3 & \text { Objetivos e contribuições } & 16\end{array}$

2 Fundamentação Teórica 17

$\begin{array}{ll}2.1 \text { Geradores de altas frequências } & 17\end{array}$

2.1.1Mistura óptica 18

$\begin{array}{ll}2.2 \text { Detectores de altas frequências } & 19\end{array}$

2.2.1Diodo Schottky 20

2.3 Geração de ondas na banda EHF 20

2.4 Modulação em amplitude (AM) 23

2.5 Modulação QPSK (Quadrature Phase-Shift Keying) 27

2.6 Error Vetor Magnitude (EVM) 29

2.7 O interferômetro Fabry-Pérot 30

3 Desenvolvimento do Experimento 34

3.1 Geração de altas frequências na banda EHF 34

3.2 Caracterização da antena Schottky de banda larga 37

3.2.1Resposta da Antena variando a frequência de modulação 38

3.2.2Resposta da Antena variando a distância entre Tx e Rx 41

3.3 Caracterização da Antena Schottky de banda estreita 45

3.3.1Resposta da antena de baixa frequência variando a frequência portadora 46

3.3.2Resposta da antena de baixa frequência variando a distância $\quad 48$

4 Resultados do experimento transmitindo informação 53

4.1 Resposta do EVM variando a potência da antena Tx. 53

5 Conclusões $\quad 59$

6 Referências Bibliográficas 61 


\section{Lista de figuras}

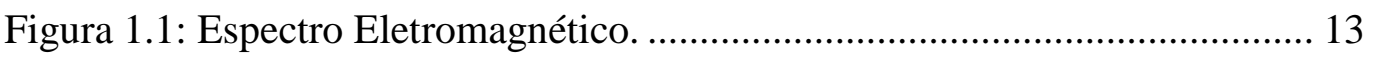

Figura 1.2: Absorção atmosférica média de ondas milimétricas [2] ................... 14

Figura 2.1: Geração de altas frequências usando uma antena

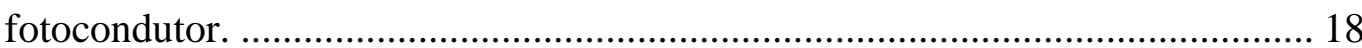

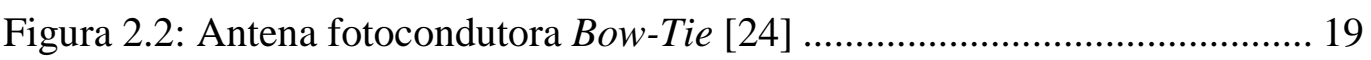

Figura 2.3 : Dispositivo equivalente ao diodo Schottky [31] ............................ 20

Figura 2.4: modulação em amplitude no tempo .................................................. 24

Figura 2.5: Modulação de amplitude no domínio da frequência......................... 24

Figura 2.6: Modulador Mach-Zhender [40] ................................................... 25

Figura 2.7: Modulação em amplitude numa banda EHF depois da

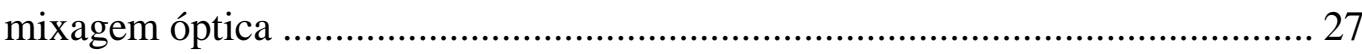

Figura 2.8: Diagrama de constelação QPSK .................................................. 28

Figura 2.9: Representação gráfica de uma medida do Error Vetor

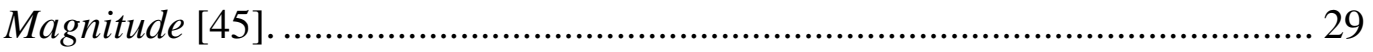

Figura 2.10 feixes refletidos em dois espelhos com distância "d" ...................... 31

Figura 3.1: Configuração do experimento para a geração e detecção de ondas na banda EHF.

Figura 3.2: Comprimento de onda do L1 em 1550,5128 nm (Mkr A) e do

L2 em 1551,312 nm (Mkr B), cuja diferença é de 0,7992 nm (Mkr B-A).

A potência óptica dos dois lasers é de $-17.36 \mathrm{dBm}$. 36

Figura 3.3: Medidas do OSA dos comprimentos de ondas nas diferentes frequências portadoras. 36

Figura 3.4: Caracterização do modulador de amplitude variando o BIAS com uma fonte DC.

Figura 3.5: Comparação das potências das diferentes frequências portadoras. 40

Figura 3.6: Comparação da Relação sinal/ruído das tabelas 3.3 até 3.5. 41

Figura 3.7: Resposta da Antena para uma portadora de $100 \mathrm{GHz}$ em função da distância. (a), (b), (c), (d) e (e) para diferentes frequências de modulação; (f) todas as medidas juntas. 
Figura 3.8: Resposta da Antena para uma portadora de $200 \mathrm{GHz}$ em função da distância. (a), (b), (c), (d) e (e) para diferentes frequências de modulação; (f) todas as medidas juntas

Figura 3.9: Resposta da Antena para uma frequência portadora de 300

$\mathrm{GHz}$ em função da distância até $11 \mathrm{~cm}$ com diferentes frequências de modulação

Figura 3.10: Configuração no laboratório para gerar e detectar ondas no

espectro EHF com uma antena receptora de baixa frequência. 46

Figura 3.11: Sinal sobre o ruído com relação à frequência portadora. 47

Figura 3.12: Resposta em potência da antena com relação à distância.

Figura 3.13: Comparação de SNR das duas antenas receptoras variando a frequência da portadora.

Figura 3.14: Sinal modulada e Sinal não modulada em relação à frequência.

Figura 4.1: Variação do EVM em relação à potência óptica da antena Tx......... 54

Figura 4.2: EVM com relação à distância. 55

Figura 4.3: resposta do EVM com relação aos níveis das potências obtidas na Figura 3.12 56

Figura 4.4: EVM e Potência de recepção com relação à distância. 


\section{Lista de tabelas}

Tabela 2.1: Representação vetorial de cada símbolo na constelação : 28

Tabela 2. 2.2: requerimento mínimo para o Error Vetor Magnitude [46]... 30

Tabela 3.1: Comprimentos de ondas resultantes para gerar frequências separadas por $100 \mathrm{GHz}$.

Tabela 3.2: Potência do sinal detectado na antena $\mathrm{Rx}$ em $100 \mathrm{GHz}$ de portadora.

Tabela 3.3: Potência do sinal detectado na antena Rx em $200 \mathrm{GHz}$ de portadora.

Tabela 3.4: Potência do sinal detectado na antena Rx em $300 \mathrm{GHz}$ de portadora.

Tabela 3.5: Potência do sinal detectado na antena Rx em $400 \mathrm{GHz}$ de portadora.

Tabela 3.6: Resposta da antena de baixa frequência para diferentes frequências portadoras.

Tabela 3.7 Campo Próximo para os comprimentos de onda de 100, 200 e 300

$\mathrm{GHz}$ 48

Tabela 3.8 Especificações das antenas de alta e baixa frequência [54]. 50

Tabela 4.1: Resultados do EVM variando a potência óptica da antena Tx 53 


\section{Acrônimos}

\begin{tabular}{|c|c|}
\hline EHF & Extremely high frequency \\
\hline THF & Tremendously high frequency \\
\hline GHz & Gigahertz \\
\hline $\mathbf{M H z}$ & Megahertz \\
\hline $\mathbf{C W}$ & Continuous Wave \\
\hline LT-GaAs & Low-temperature grown gallium arsenide \\
\hline SI-GaAs & Semi-Insulating gallium arsenide \\
\hline EVM & Error Vector Magnitude \\
\hline E-TM & E-Utran Test Model \\
\hline QPSK & Quadrature phase-shift keying \\
\hline 3GPP & 3rd Generation Partnership Project \\
\hline ETSI & European Telecomunications Standards Institute \\
\hline EDFA & Erbium Doped Fiber Amplifier \\
\hline VOA & Variable Optical Attenuattor \\
\hline BS & Beam Splitter \\
\hline PA-Tx & Photoconductive Antena transmissora \\
\hline SD-Rx & Schottky diode Antena receptora \\
\hline $\mathbf{P C}$ & Polarization controller \\
\hline MZ-AM & Mach-Zehnder Amplitude modulator \\
\hline EA & Electrical amplifier \\
\hline OSA & Optical spectrum analyzer \\
\hline ESA & Electrical spectrum analyzer \\
\hline PM & Power meter \\
\hline PTx & Potência de transmissão \\
\hline SNR & Signal to noise ratio \\
\hline VSG & Vector signal generator \\
\hline VSA & Vector signal analyzer \\
\hline
\end{tabular}


Não se pode aprender nada de uma lição que não seja acompanhada por dor, já que não se pode conseguir nada sem um sacrifício. Mas quando você aguenta essa dor e a supera, as pessoas conseguem um coração forte que não perde para nada. Sim, um coração de aço. 


\section{Introdução}

A tendência tecnológica de uma comunicação mais rápida e por meios sem fios está evoluindo nestes últimos anos. O aumento das aplicações e da quantidade de informação que viaja através deste tipo de meio também estão aumentando, implicando assim o começo da saturação das bandas utilizadas, e é devido a isso que as pesquisas nas bandas milimétricas (EHF - Extremely High Frequency) e submilimétricas (THF - Tremendously High Frequency) estão sendo desenvolvidas para melhorar a eficiência espectral nas comunicações.

A banda milimétrica ou EHF (Extremely High Frequency) tem uma faixa de frequência que vai desde os $30 \mathrm{GHz}$ (Gigahertz) até os $300 \mathrm{GHz}$ como é ilustrado na Figura 1.1 Ela é denominada banda milimétrica pelos comprimentos de ondas que variam desde $10 \mathrm{~mm}$ (milímetros) até $1 \mathrm{~mm}$. Ondas eletromagnéticas nesta faixa de frequência tem muita atenuação na atmosfera e por isso são usadas em comunicações de curta distância. No espectro eletromagnético a faixa Terahertz fica numa região entre a banda de micro-ondas e a banda infravermelha, ou seja, a banda EHF fica entre o campo da fotônica e da eletrônica.

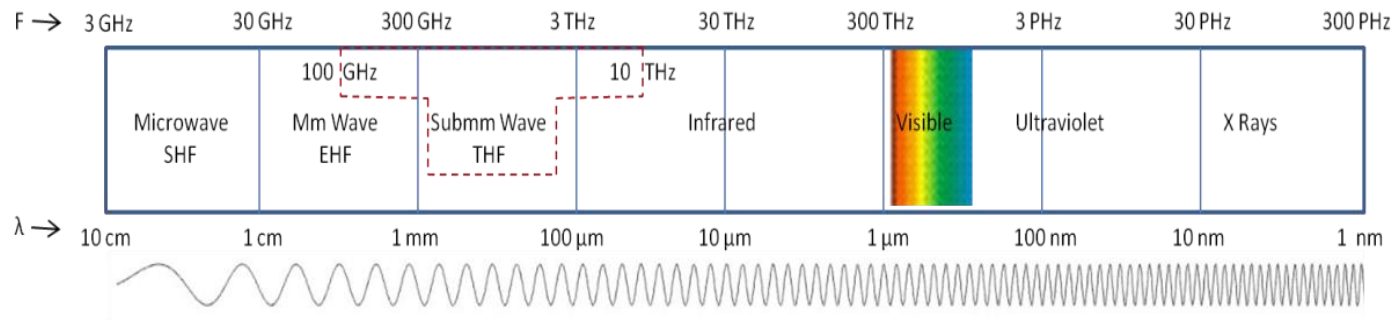

Figura 1.1: Espectro Eletromagnético.

Duas das características mais importantes das ondas Terahertz são: em primeiro lugar, a capacidade de penetrar certos materiais como tecidos, papel, etc.; e também, o fato de que nesta faixa do espectro existem moléculas com uma 
absorção quantificável fazendo possível a identificação de compostos presentes no material atravessado por estas ondas [1].

Outra característica, que compartilha com suas bandas vizinhas (banda de microondas e banda infravermelha), é que sua radiação é não ionizante, em outras palavras, não tem muita energia para ionizar uma molécula, mas só a suficiente para excitar o movimento do elétron fazendo-o mudar a um estado de energia superior. Com isso essas ondas têm efeitos biológicos bastante reduzidos, daí sua importância nos equipamentos de detecção de armas ou materiais tóxicos e drogas.

A banda EHF precisa ter uma linha de vista no espaço livre, por que a perda vai se incrementando com a distância entre as duas antenas, tendo assim um melhor desempenho em comunicações de curta distância devido aos efeitos de propagação que influenciam nas ondas milimétricas como é mostrado na seguinte imagem [2].

Wavelength $(\mathrm{mm})$

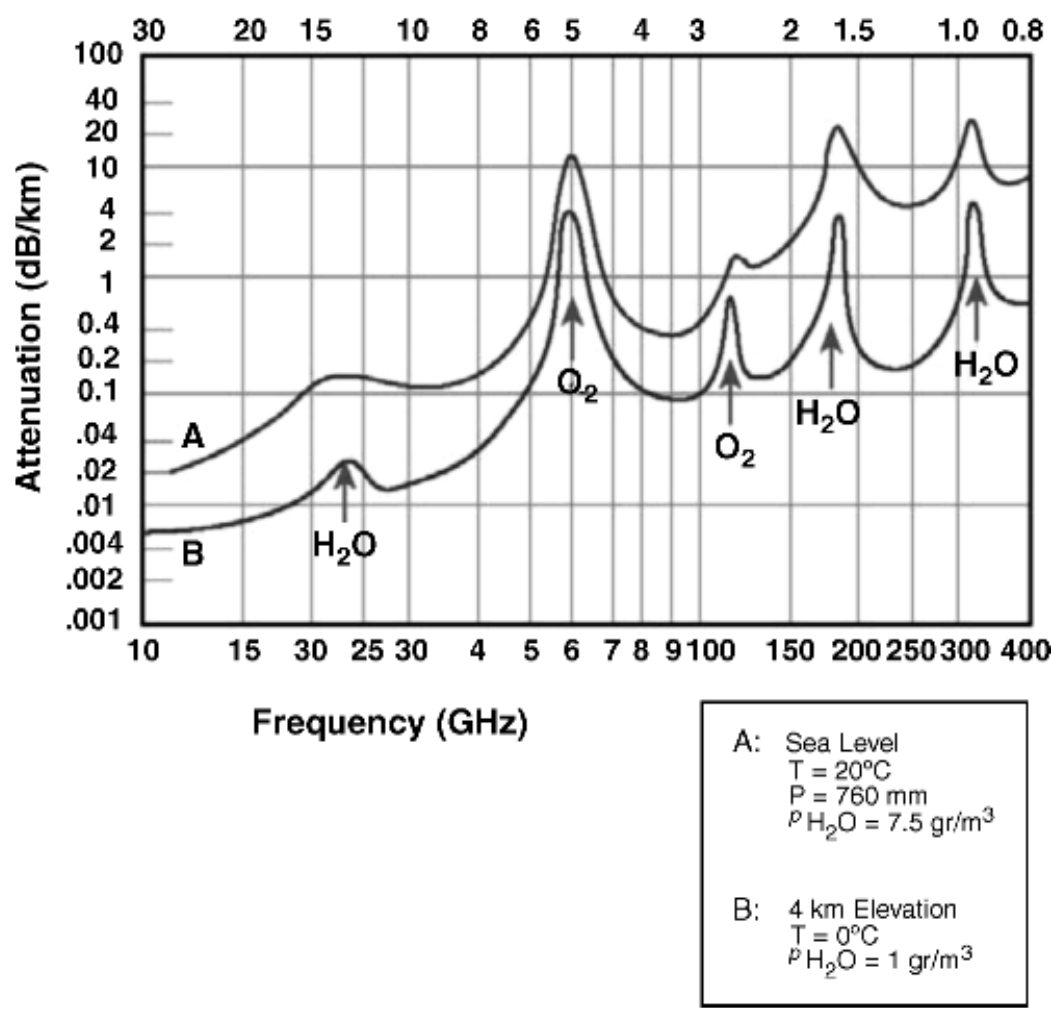

Figura 1.2: Absorção atmosférica média de ondas milimétricas [2]

Estas características das frequências da banda EHF, despertaram muito interesse nas possibilidades de estudo em diferentes áreas como em biologia, 
medicina, comunicações, segurança, radares, espectroscopia, astronomia, etc. [3]$[6]$.

\subsection{Descrição do problema}

O estudo de bandas de EHF para a transmissão e recepção de informação vem-se realizando há alguns anos, com o objetivo de aumentar a largura de banda e melhorar a velocidade de transmissão mediante meios sem fio. Estes estudos vemse realizando devido à crescente demanda de usuários, a massiva transferência de dados e a constante necessidade de aumentar a velocidade de transmissão para estar acorde com as demandas das novas tecnologias.

A tendência tecnológica é fazer tudo mediante conexões sem fio, assim na última década as bandas de frequências mais usadas foram ocupadas chegando ao ponto de quase saturação. Nesse sentido o estudo do espectro eletromagnético de frequências mais altas (EHF) oferece um amplo campo de pesquisa e desenvolvimento.

\subsection{Estado da Arte}

Alguns trabalhos com resultados promissórios já foram publicados os quais demonstram a viabilidade da transmissão de dados em THz.

No ano 2015, o trabalho da referência [7] desenvolvido por Tadao Nagatsuma, estudou as ondas $\mathrm{THz}$ para envio de informação. $\mathrm{O}$ experimento foi desenvolvido mediante a teoria da fotônica para gerar altas frequências. Para a parte da transmissão foi usado um gerador de sinais ópticas, um modulador óptico, um fotodiodo e uma antena. Dois lasers, um deles com comprimento de onda variável e u outro com comprimento de onda fixo, trabalhando em diferentes comprimentos de onda, são injetados no fotodiodo onde a radiação em $\mathrm{THz}$ é gerada, obtendo assim uma transmissão de $50 \mathrm{Gbit} / \mathrm{s}$ para uma distância de 20 metros na banda de $300 \mathrm{GHz}$ com modulação QPSK.

No mesmo ano, presentou-se outro trabalho [8], desenvolvido por G. Ducournau, onde é demonstrada a transmissão de dados a $32 \mathrm{Gbit} / \mathrm{s}$ numa banda de 
385 Ghz com modulação QPSK. A modulação QPSK foi criada no domínio óptico para uma das fontes ópticas, a qual foi misturada com outra fonte óptica de onda continua com uma frequência de separação de $385 \mathrm{GHz}$. Os sinais ópticos foram amplificados por um EDFA para depois serem injetados num fotodiodo. O sinal resultante é enviado para um photomixer obtendo assim o sinal em $\mathrm{THz}$ a uma distância de 0,4 metros.

No ano 2016, o paper "Real-time 100-Gbit/s QPSK Transmission UsingPhotonics-based 300-GHz-band Wireless Link" [9] desenvolvido na universidade de Osaka, presenta um estudo na banda de $300 \mathrm{GHz}$, uma transmissão de $100 \mathrm{Gbit} / \mathrm{s}$ com uma modulação QPSK numa distância de 5 a 10 centímetros num meio sem fio.

\subsection{Objetivos e contribuições}

Este trabalho estuda a transmissão de dados LTE, em frequências portadoras a partir de $100 \mathrm{GHz}$ dentro da banda EHF, geradas mediante uma arquitetura baseada no batimento de dois lasers, que são combinados mediante um Beam Splitter, num meio não linear. O batimento dos dois lasers, com diferentes comprimentos de onda e com a mesma potência, interagem com uma antena fotocondutora dando como resultado uma frequência na ordem de Gigahertz. Frequências portadoras de 100, 200, 300 e $400 \mathrm{GHz}$ foram geradas.

No experimento utilizaram-se dois tipos de diodos receptores, um de banda larga $(<4 \mathrm{GHz})$ e outro de banda estreita $(<1 \mathrm{MHz})$. As duas antenas foram testadas em diferentes distâncias e com diferentes frequências de portadora para verificar qual delas tinha o melhor desempenho na banda EHF para poder realizar a transmissão de dados. 


\section{Fundamentação Teórica}

Nesta parte do trabalho se apresentara os principais conceitos teóricos e as tecnologias que foram utilizadas para poder realizar esta dissertação. Na seção 2.1 são descritos os principais métodos de geração de altas frequências na banda EHF. Subsequentemente, na seção 2.2 são descritas as formas de detecção e os detectores principais de frequências altas. A seção 2.3 descreve a matemática que envolve a criação de ondas na banda EHF; também as formas de modulação que foram usadas nos experimentos são descritas na seção 2.4 e 2.5. Por último, na seção 2.6 descreve-se o método de verificar a transmissão de dados utilizada no trabalho e, por último, na secção 2,7 descreve-se um efeito de tipo Fabry-Perot observado quando se realizaram as medições variando a distância entre as antenas.

\subsection{Geradores de altas frequências}

Existem dois métodos mais utilizados para gerar frequências dentro da banda EHF. Um deles emprega fontes de ondas contínuas, ou CW, pelo acrônimo em inglês de Continuous Wave, como por exemplo: mixagem óptica (o qual foi utilizado neste trabalho) que consiste na geração de ondas de alta frequência por meio da teoria de diferença de frequências [10], laser de gás infravermelho distante [11], multiplicação de frequências de micro-ondas [12], laser de germânio tipo $p$ [13], laser de cascata quântica (QCL) [14], Backward Wave Oscillator (BWO) [15] e laser de elétron livre [16], [17]. O outro método para produzir frequências altas emprega fontes lasers pulsados gerando pulsos de luz com duração extremamente curta que, quando detectados, geram ondas eletromagnéticas de alta frequência [18] como, por exemplo: Retificação óptica [19], [20], Antenas fotocondutivas [19], [20], [21], pulsos de THz de banda ultra larga [24], [25].

Este trabalho concentra-se numa fonte de onda contínua na banda EHF baseada na mixagem óptica que será descrita a seguir. 


\subsubsection{Mistura óptica}

Chamado também de: conversão óptico-heteródino; utiliza a combinação de duas fontes de ondas contínuas com diferentes frequências, fazendo um batimento óptico entre elas. O sinal resultante é dado pela interferência das ondas da frequência dos lasers ao ingressar na antena fotocondutor, tendo assim uma emissão de radiação continua de ondas na banda EHF, como é mostrado na Figura 2.1.

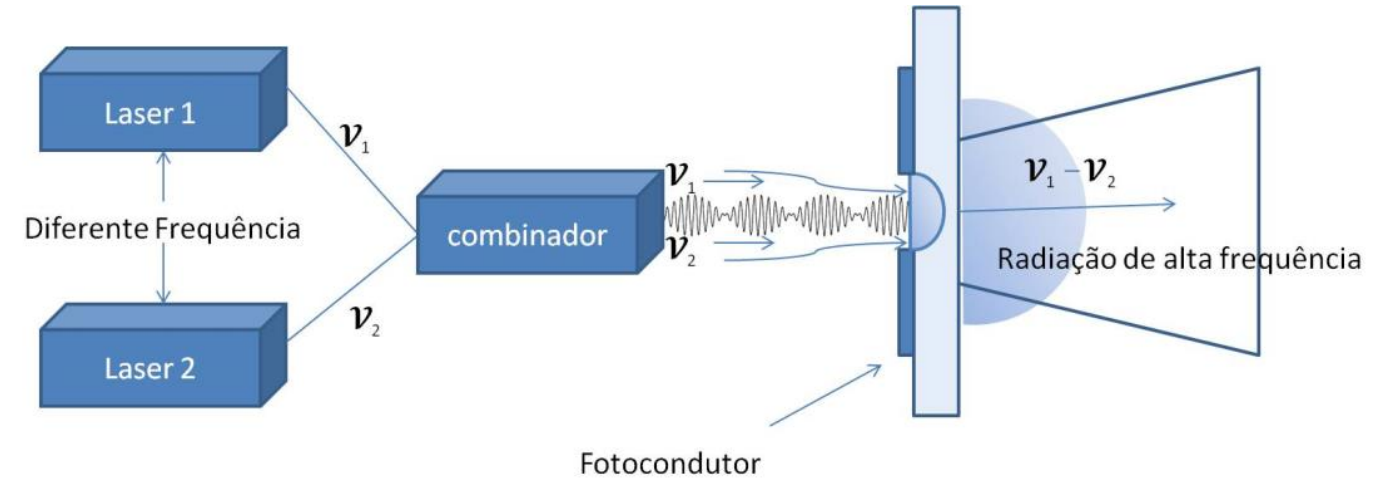

Figura 2.1: Geração de altas frequências usando uma antena fotocondutora.

As principais vantagens de usar a técnica de mixagem óptica são que o experimento não precisa de muito espaço, é compacto e sintonizável, ademais que tem baixo custo. Mas a principal desvantagem é a potência de saída que é baixa tendo em conta as outras formas de gerar altas frequências [12].

O elemento principal na mixagem óptica é a antena fotocondutora. O fotocondutor tem uma estrutura de metal sobre uma camada de LT-GaAs (Lowtemperature grown gallium arsenide) criada num substrato de SI-GaAs (SemiInsulating GaAs - GaAs Semi isolante). Também tem uma lente hiper-hemisférica de silício que é ligada ao lado posterior do substrato [12].

A antena fotocondutora usada nesta apresentação é do tipo bow-tie e trabalha com uma tensão DC de polarização. A antena bow-tie é uma antena dipolo impressa numa estrutura nanométrica de InGaAs, a qual trabalha conjuntamente com uma lente de silício, que cumpre a função de colimar a onda emitida como mostra a Figura 2.2. O material InGaAs é sensível à luz na faixa das telecomunicações ópticas, entre $1200 \mathrm{~nm}$ e $1600 \mathrm{~nm}$. 


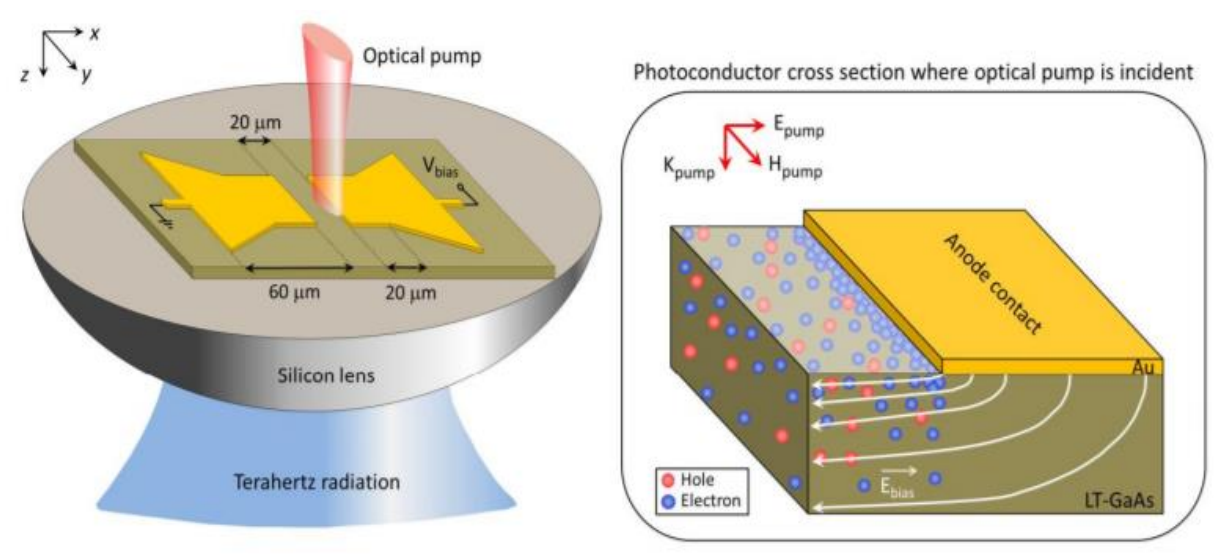

Figura 2.2: Antena fotocondutora Bow-Tie [26]

Quando a luz que é gerada por os dois lasers interage com o semicondutor, são criados portadores, donde a corrente elétrica é proporcional à intensidade da luz. As portadoras criadas neste processo tem o tempo de vida muito curto, tornando possível converter uma modulação muito rápida da intensidade da luz em uma corrente modulada na mesma frequência, gerando assim a onda na banda EHF que é emitida pela antena.

O batimento dos lasers (laser 1 e laser 2) é convertido diretamente numa corrente senoidal de alta frequência cuja diferença entre as duas frequências ópticas gera as ondas em EHF [26] .

\subsection{Detectores de altas frequências}

Para a detecção de frequências na banda EHF existem várias técnicas de detecção. Os detectores térmicos, que entre os mais comuns estão: os bolômetros [27], detectores piroelétricos [28], [29], as células de Golay [30], [31], os detectores MOSFET (metal oxide semiconductor field effect transistor) [32]. Por outro lado, existe também a detecção heteródina feita por diodo Schottky [33], o qual foi utilizado neste trabalho, e os detectores supercondutores como: Fotocondutor [34], a junção Josephson SIS ou junção de tunelamento [35], [36], detectores SET (Single electron transistors) [37], [38], entre outros. 


\subsubsection{Diodo Schottky}

Os diodos detectores Schottky estão sendo usados nas bandas EHF e THF devido a sua alta sensibilidade, também a sua capacidade de poder operar em temperaturas criogênicas e de ambiente e por sua rápida resposta em tempo comparado com outros detectores, e é por isto que estes diodos são utilizados para a detecção direta da radiação de ondas de alta frequência [39].

A principal característica dos diodos Schottky, chamados assim pelo alemão Walter Schottky, é que eles têm uma barreira de potencial baixa o que faz com que eles sejam muito sensíveis para detectar sinais muito fracos.

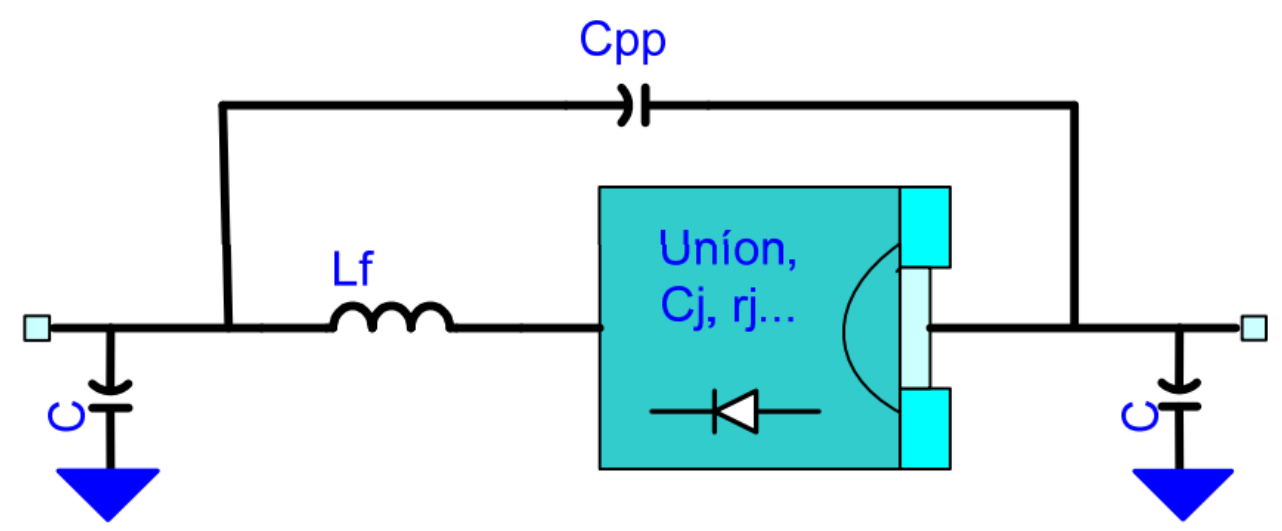

Figura 2.3 : Dispositivo equivalente ao diodo Schottky [33].

\subsection{Geração de ondas na banda EHF}

Como foi explicado na secção 2.1.1, os as altas frequências são criados (neste trabalho) por meio da técnica da mixagem óptica, o qual consiste em dois lasers de diferentes frequências que iluminam uma antena fotocondutora. A soma de duas ondas de frequências diferentes produz um batimento com diferença de frequência em uma determinada região de EHF.

Quando a luz interage com o semicondutor da antena, os portadores são criados de maneira que a corrente elétrica é proporcional à intensidade da luz , 
convertendo assim o batimento dos dois lasers numa corrente de alta frequência. [40].

Por meio da teoria da interferência de duas ondas, ao combinar duas frequências geradas por dois lasers como se mostra na Figura 2.1, os dois feixes são combinados, tendo como resultado a soma dos dois campos elétricos em um ponto dado,

$$
E(t)=E_{1}(t)+E_{2}(t)
$$

Onde $E_{1}(t)$ e $E_{2}(t)$ estão representando os campos elétricos dos lasers 1 e 2 correspondentemente, os quais podem ser descritos por,

$$
\begin{aligned}
& E_{1}(t)=a_{1} \cos \left(2 \pi v_{1} t+\phi_{1}\right), \\
& E_{2}(t)=a_{2} \cos \left(2 \pi v_{2} t+\phi_{2}\right),
\end{aligned}
$$

Nas equações (2) e (3) o campo que gera cada laser é representado pelas amplitudes $a_{1} e a_{2}$, as frequências por $v_{1} e v_{2}$, e as fases por $\phi_{1} e \phi_{2}$.

Dado que a intensidade é proporcional ao quadrado do campo elétrico, assumindo que os dois lasers (L1 e L2) estão com diferentes frequências, então, se tem a seguinte equação:

$$
I_{\text {óptico }}(t) \propto\left[E_{1}(t)+E_{2}(t)\right]^{2},
$$

Agora se substitui as equações (2) e (3) na equação (4),

$$
\begin{aligned}
& I_{\text {óptico }}(t) \propto(1 / 2)\left(a_{1}^{2}+a_{2}^{2}\right)+(1 / 2)\left[\cos 2\left(2 \pi v_{1} t+\phi_{1}\right)\right. \\
&\left.+\cos 2\left(2 \pi v_{2} t+\phi_{2}\right)\right] \\
&+a_{1} a_{2} \cos \left[2 \pi\left(v_{1}+v_{2}\right) t+\phi_{1}+\phi_{2}\right] \\
&+a_{1} a_{2} \cos \left[2 \pi\left(v_{1}-v_{2}\right) t+\phi_{1}-\phi_{2}\right] .
\end{aligned}
$$


$\mathrm{Na}$ equação da intensidade (5), se pode observar que o segundo, terceiro e quarto elemento da equação têm frequências muito altas para serem detectados, e é por isso que essa equação pode ser reduzida a uma expressão onde os valores possam ser analisados. A expressão é a seguinte,

$$
I_{\text {óptico }}(t)=(1 / 2)\left(a_{1}^{2}+a_{2}^{2}\right)+a_{1} a_{2} \cos \left[2 \pi\left(v_{1}-v_{2}\right) t+\phi_{1}-\phi_{2}\right] \text {. }
$$

A expressão (6) representa a intensidade da onda de luz combinada dos dois lasers.

Como é mostrado na Figura 2.2, esta intensidade do bombeamento óptico chega no fotocondutor onde cria portadoras (elétrons) produzindo uma condutância de forma proporcional ao intensidade:

$$
\sigma_{S}(t) \propto I_{\text {optico }}
$$

$\mathrm{O}$ voltagem do bias $V_{\text {bias }}$ é aplicado no fotocondutor. Então, quando a condutância fica não-nula devido à chegada do bombeamento óptico, uma corrente será induzida, proporcional à condutância e à voltagem aplicada [41]:

$$
i(t) \propto \sigma_{s}(t) V_{\text {bias }}
$$

Em outras palavras, a intensidade dos dois lasers, é convertido numa corrente de alta frequência $f_{T H z}=\left(v_{1}-v_{2}\right)$.

Agora, o campo eletromagnético irradiado em Terahertz $E_{T H z}^{r}(t)$, é proportional à aceleração dos portadores ou seja proporcional à taxa de variação da corrente. [41]

$$
\begin{gathered}
E_{T H z}^{r}(t) \propto \frac{d}{d t} i(t) \\
E_{T H z}^{r}(t) \propto 2 \pi \mathrm{f}_{\mathrm{THz}} \mathrm{V}_{\text {bias }} \mathrm{a}_{1} \mathrm{a}_{2} \sin \left(2 \pi f_{T H z} t+\Delta \phi\right)
\end{gathered}
$$




\subsection{Modulação em amplitude (AM)}

Na modulação por amplitude, a amplitude do sinal portadora varia de acordo com as variações de amplitude do sinal modulador, neste processo, a frequência da portadora e a fase mantêm seus valores.

O sinal da portadora sem modulação pode ser representado pela seguinte equação:

$$
f_{c}(t)=\sin \left(2 \pi f_{c} t\right)
$$

Onde " $f_{c}$ " é a frequência e "t" é o tempo.

E o sinal modulador é representado pela equação:

$$
f_{m}(t)=1+\sin \left(2 \pi f_{m} t\right)
$$

A modulação é dada pela multiplicação do sinal modulador com o sinal da portadora obtendo a seguinte equação:

$$
\begin{gathered}
f_{A M}(t)=f_{c}(t) x f_{m}(t) . \\
f_{A M}(t)=\left(\sin \left(2 \pi f_{c} t\right)\right) x\left(1+\sin \left(2 \pi f_{m} t\right)\right)
\end{gathered}
$$

A representação das equações é mostrada na Figura 2.4: 

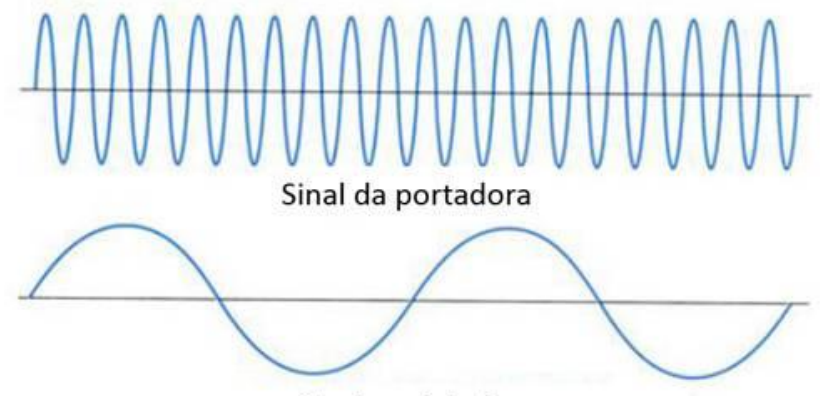

Sinal modulador

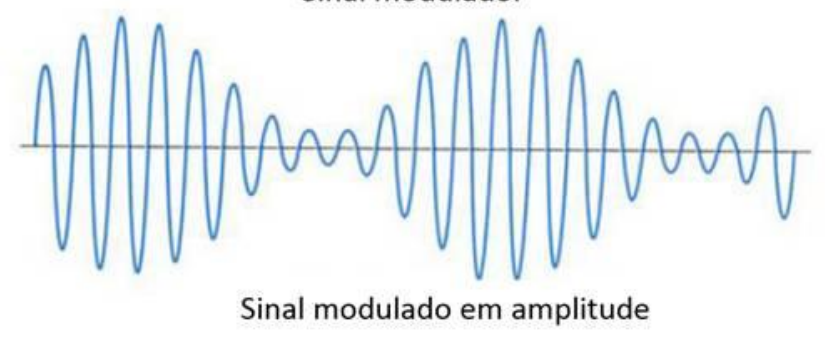

Figura 2.4: modulação em amplitude no tempo

$$
\begin{gathered}
f_{A M}(t)=\sin \left(2 \pi f_{c} t\right)+\frac{1}{2} * \sin \left(2 \pi\left(f_{c}+f_{m}\right) t\right) \\
+\frac{1}{2} x \sin \left(2 \pi\left(f_{c}-f_{m}\right) t\right)
\end{gathered}
$$

$f_{c}+f_{m}$, uma banda inferior $f_{c}-f_{m}$ e o tom da frequência portadora $f_{c}$

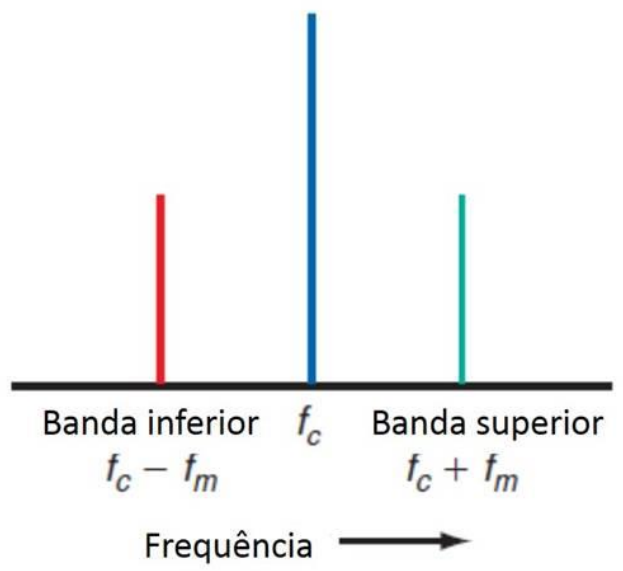

Figura 2.5: Modulação de amplitude no domínio da frequência

A modulação de amplitude tem quase a mesma teoria matemática que a modulação em fase, mas a diferença está em que o AM utiliza (na configuração) um interferômetro de Mach-Zehnder [42]. O modulador de amplitude Mach- 
Zehnder é como um interferômetro Mach-Zehnder, ele tem dois braços onde o mesmo sinal é enviado pelos dois braços como é mostrado na Figura 2.6.

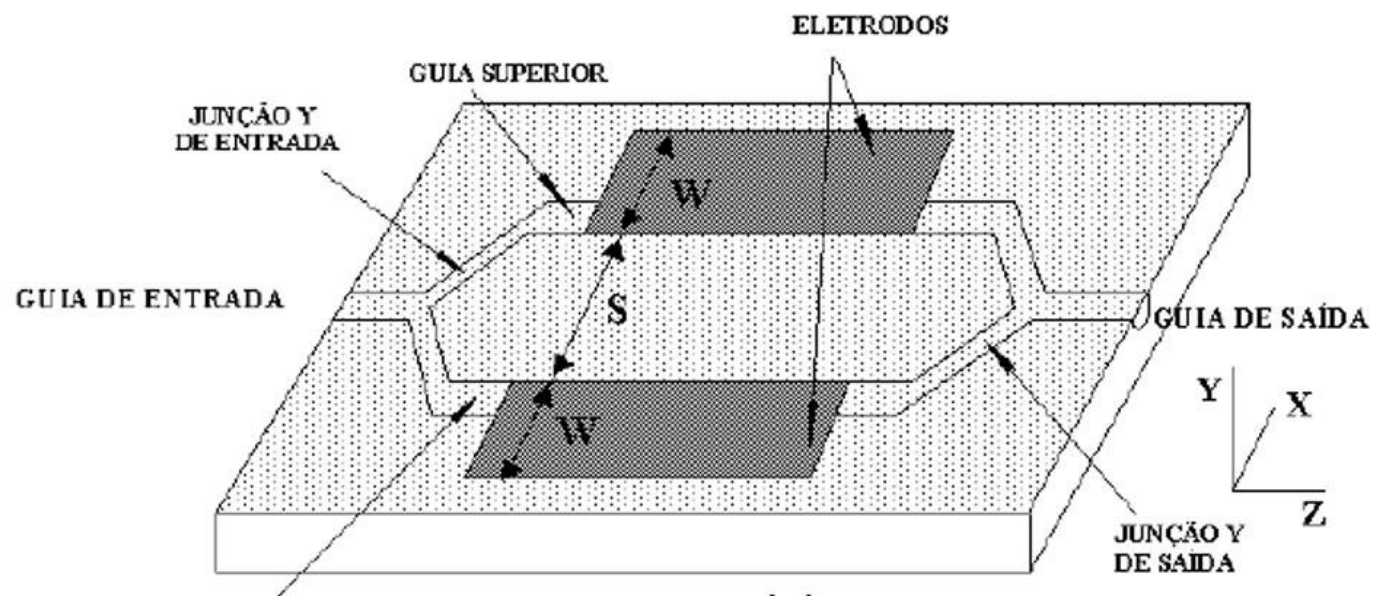

Figura 2.6: Modulador Mach-Zehnder [43].

O campo óptico na guia de entrada se pode expressar da seguinte maneira [43]:

$$
E_{i}(t)=a_{i} e^{-j v_{c} t}
$$

Onde $a_{i}$ e $v_{c}$ representam, respectivamente, a amplitude e a frequência do sinal óptico.

Então o sinal $E_{0}(t)$ resultante da soma dos dois feixes luminosos de saída será representado pela equação:

$$
E_{0}(t)=L \times \frac{a_{i}}{2} \times\left(e^{-j\left(v_{c} t+\phi_{1}\right)}+e^{-j\left(v_{c} t+\phi_{2}\right)}\right) .
$$

Onde L contabiliza as perdas por inserção do guia de onda óptico [43] .

O campo óptico pode-se descrever da seguinte forma tendo em conta a equação (18) [43]: 


$$
\begin{aligned}
E_{0}(t) & =L \times \frac{a_{i}}{2} \times\left(e^{-j v_{c} t} e^{-j \phi_{1}}+e^{-j v_{c} t} e^{-j \phi_{2}}\right) . \\
& =L \times \frac{a_{i}}{2} \times e^{-j v_{c} t}\left(e^{-j \phi_{1}}+e^{-j \phi_{2}}\right) . \\
& =L \times \frac{a_{i}}{2} \times e^{-j v_{c} t} \times e^{-j \phi_{0}}\left(e^{-j \frac{\Delta \phi}{2}}+e^{j \frac{\Delta \phi}{2}}\right) .
\end{aligned}
$$

Onde $\Delta \phi=\phi_{1}-\phi_{2}$ é a diferença de fase entre os braços do modulador e $\phi_{0}=\frac{\phi_{1}+\phi_{2}}{2}$ é o atraso médio de fase dos dois braços do modulador, então [43] :

$$
E_{0}(t)=L \times \frac{a_{i}}{2} \times e^{-j v_{c} t} \times e^{-j \phi_{0}} \times \cos \left(\frac{\Delta \phi}{2}\right)
$$

Substituindo o campo de entrada descrito na equação (15), com a equação (20) fica da seguinte forma:

$$
E_{0}(t)=L \times E_{i}(t) \times \cos \left(\frac{\Delta \phi}{2}\right) \times e^{-j \phi_{0}} .
$$

Fazendo a substituição com diferença de fase entre os braços e o atraso médio tem-se [43] :

$$
E_{0}(t)=L \times E_{i}(t) \times \cos \left(\frac{\phi_{1}-\phi_{2}}{2}\right) \times e^{-j\left(\frac{\phi_{1}+\phi_{2}}{2}\right)} .
$$

Analisando a equação (22) pode-se concluir que o sinal óptico $E_{0}(t)$ depende diretamente da diferença de fase dos sinais ópticos que trafegam entre os dois braços do modulador [43] .

Neste trabalho a modulação foi feita só em um laser, e como é mostrada na equação (6), a intensidade total depende da amplitude e da fase dos dois lasers. Tendo em conta que as fases dos lasers não variam, então a amplitude do sinal resultante depende da amplitude dos lasers. Assim se mantemos um dos lasers com 
amplitude fixa $\left(a_{1}\right)$ e modulamos o outro $\left(a_{2}\right)$, temos como resultado um sinal dentro da banda EHF modulado em amplitude com o mesmo sinal $a_{2}$.
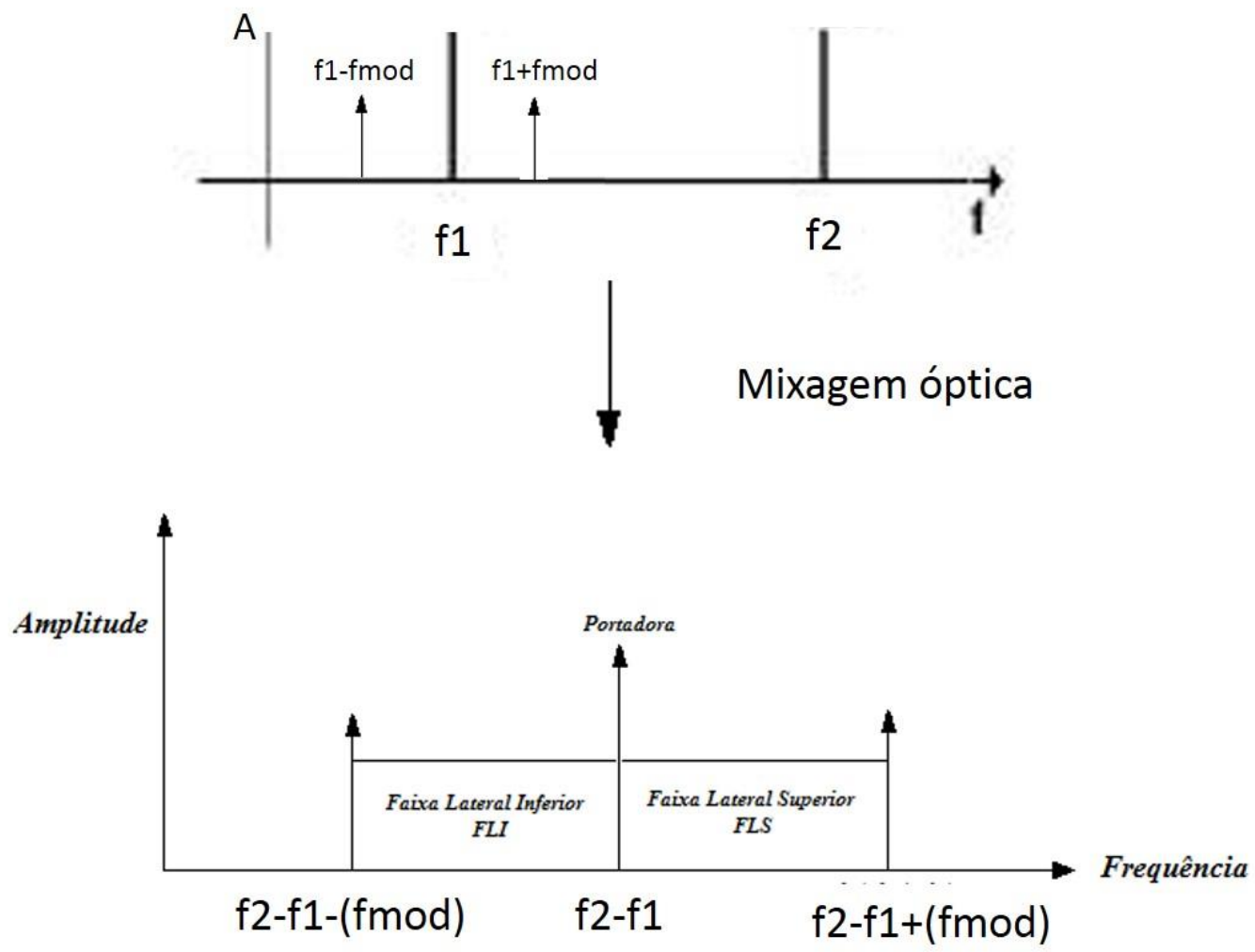

Figura 2.7: Modulação em amplitude numa banda EHF depois da mixagem óptica

\subsection{Modulação QPSK (Quadrature Phase-Shift Keying)}

A modulação QPSK é uma técnica multi-nível que trabalha em fase e quadratura, donde o sinal ou símbolo carrega dois bits, tendo assim uma maior eficiência espectral. Nesta modulação ao trabalhar com dois bits se tem 4 tipos de símbolos possíveis, tendo como resultado 4 valores diferentes de fase que estão separadas por $90^{\circ}$ [44].

Cada símbolo pode ser representado por sinais ortogonais em um diagrama vetorial o qual é chamado diagrama de constelação. Os símbolos são obtidos pela projeção dos vetores no plano de constelação, sendo a projeção I (In Phase) e Q (Quadrature) [45], como se mostra na Figura 2.8: 


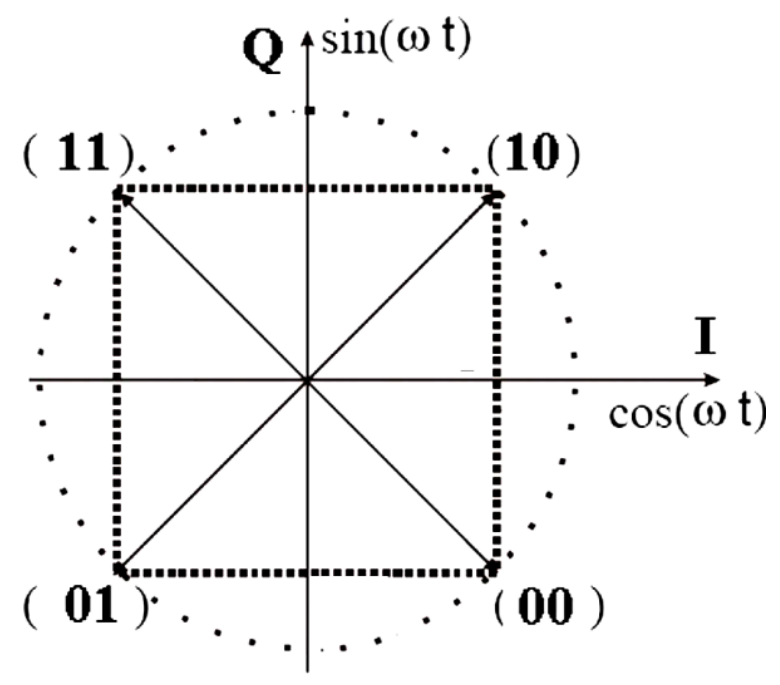

Figura 2.8: Diagrama de constelação QPSK .

Cada bit na constelação pode ser expresso pela seguinte equação de forma geral:

$$
S_{i}(t)=\sqrt{\frac{2 E}{T}} \cos \left[(2 i-1) \frac{\pi}{4}\right] \cos 2 \pi f_{c} t-\sqrt{\frac{2 E}{T}} \operatorname{sen}\left[(2 i-1) \frac{\pi}{4}\right] \operatorname{sen} 2 \pi f_{c} t
$$

Onde T é o período de símbolo, E é a energia de símbolo, $\mathrm{i}=1,2,3,4$ e $f_{c}$ é a frequência da portadora.

Na Tabela 2.1 mostram-se as equações que representam a cada ponto na constelação, segundo a fase, o Bit e o símbolo (onde $w_{c}=2 \pi f_{c}$ ).

Tabela 2.1: Representação vetorial de cada símbolo na constelação :

\begin{tabular}{|l|c|c|c|}
\hline $\mathrm{S}(\mathrm{t})$ & Fase & Bits & Símb. \\
\hline$A\left[\cos \left(w_{c} t+\frac{\pi}{4}\right)\right]=A\left[\cos \left(w_{c} t\right) \cos \left(\frac{\pi}{4}\right)-\sin \left(w_{c} t\right) \sin \left(\frac{\pi}{4}\right)\right]$ & $\frac{\pi}{4}$ & 00 & $\mathrm{~S} 1$ \\
\hline$A\left[\cos \left(w_{c} t+\frac{3 \pi}{4}\right)\right]=A\left[\cos \left(w_{c} t\right) \cos \left(\frac{3 \pi}{4}\right)-\sin \left(w_{c} t\right) \sin \left(\frac{3 \pi}{4}\right)\right]$ & $\frac{3 \pi}{4}$ & 01 & $\mathrm{~S} 2$ \\
\hline$A\left[\cos \left(w_{c} t+\frac{5 \pi}{4}\right)\right]=A\left[\cos \left(w_{c} t\right) \cos \left(\frac{5 \pi}{4}\right)-\sin \left(w_{c} t\right) \sin \left(\frac{5 \pi}{4}\right)\right]$ & $\frac{5 \pi}{4}$ & 10 & $\mathrm{~S} 3$ \\
\hline
\end{tabular}




\begin{tabular}{|l|l|l|l|l|}
\hline$A\left[\cos \left(w_{c} t+\frac{7 \pi}{4}\right)\right]=A\left[\cos \left(w_{c} t\right) \cos \left(\frac{7 \pi}{4}\right)-\sin \left(w_{c} t\right) \sin \left(\frac{7 \pi}{4}\right)\right]$ & $\frac{7 \pi}{4}$ & 11 & S4 \\
\hline
\end{tabular}

\subsection{Error Vetor Magnitude (EVM)}

Ao trabalhar com uma modulação em multi-nível, que trabalha em fase e quadratura, cujos símbolos são representados numa constelação, utiliza-se o EVM como métrica de rendimento para avaliar a qualidade do sinal modulada por vetor [46].

EVM é a qualidade do sinal em modulações digitais que avalia os vetores modulados do sinal. Os valores do EVM são obtidos mediante a deferência de um valor de voltagem esperado do símbolo do sinal demodulado e o valor do símbolo obtido, e ao avaliar os erros na amplitude e a fase, é mais recomendável usar o padrão EVM que o Bit Error Rate (BER) [47].

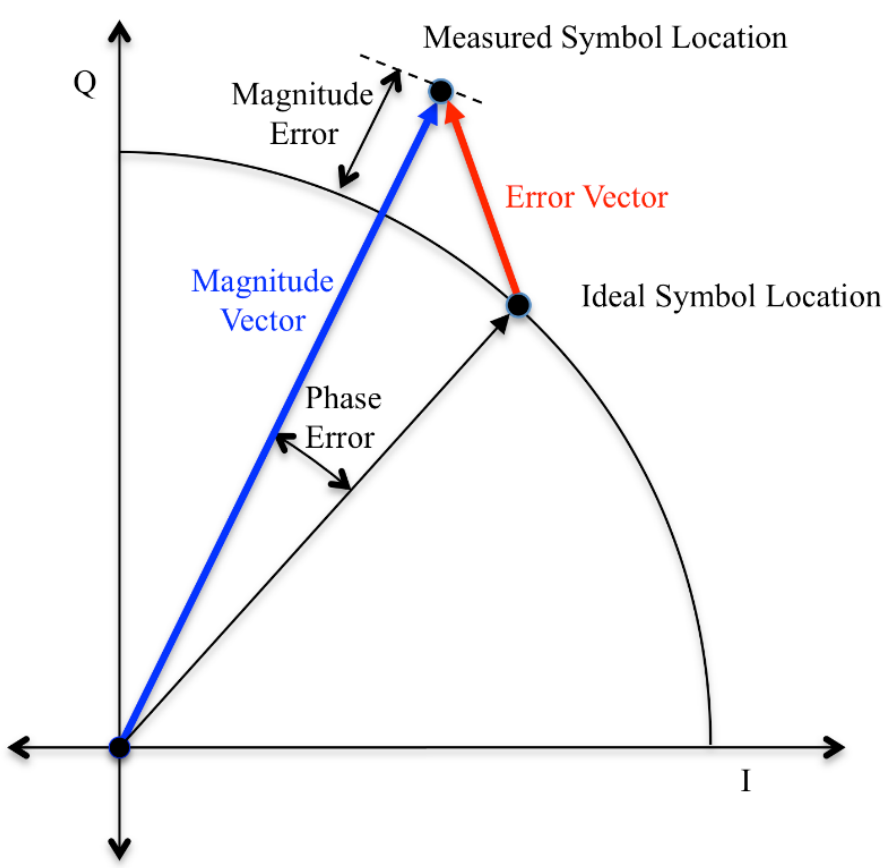

Figura 2.9: Representação gráfica de uma medida do Error Vetor Magnitude [48]. 
O EVM é simplesmente a relação da magnitude deste "Error Vector" (representada na Figura 2.9 por uma flecha vermelha) e a magnitude do símbolo ideal (flecha preta) [48] .

A magnitude desta diferença está representada pela seguinte equação [46]:

$$
E V M_{R M S}=\frac{\frac{1}{N} \sum_{n=1}^{N}\left|S_{n}-S_{0, n}\right|^{2}}{\frac{1}{N} \sum_{n=1}^{N}\left|S_{0, n}\right|^{2}}
$$

Onde $S_{n}$ é o n-th símbolo normalizado no fluxo de símbolos medidos, $S_{0}$ é o ponto ideal normalizado da constelação do n-th símbolo e $\mathrm{N}$ é o número de símbolos únicos na constelação [46] .

Em nosso experimento utilizou-se o padrão E-TM 1.1 (E-UTRAN Test Model), onde os valores mínimos aceitados para as medidas do EVM numa modulação QPSK já foram estabelecidos pela 3GPP (3rd Generation Partnership Project) e ETSI (European Telecomunications Standards Institute) [49], e são mostrados na Tabela 2. 2.2.

Tabela 2. 2.2: requerimento mínimo para o Error Vetor Magnitude [49]

\begin{tabular}{|c|c|c|c|}
\hline Modulação & $\begin{array}{c}\text { Unidade de } \\
\text { medida }\end{array}$ & Nível do EVM & $\begin{array}{c}\text { Sinal de } \\
\text { referência EVM }\end{array}$ \\
\hline QPSK ou BPSK & $\%$ & 17,5 & {$[17,5]$} \\
\hline
\end{tabular}

\subsection{O interferômetro Fabry-Pérot}

Ao ter duas antenas separadas por uma distância $x$, elas atuam como dois espelhos numa cavidade de Fabry-Perot, produzindo interferências construtivas e destrutivas. Assim as interferências construtivas acontecem quando a distância de separação $x$ é um múltiplo de $\lambda / 2$, onde $\lambda$ é o comprimento de onda da portadora na banda EHF. É por isso que os conceitos fundamentais do interferômetro são explicados nesta parte. 
O interferômetro normalmente está constituído por dois espelhos que refletem o sinal. Quando a luz chegar ao primeiro espelho com um ângulo $\alpha$, ocasiona que parte do feixe seja transmitida e outra parte seja refletida e assim sucessivamente como mostra na Figura 2.10.

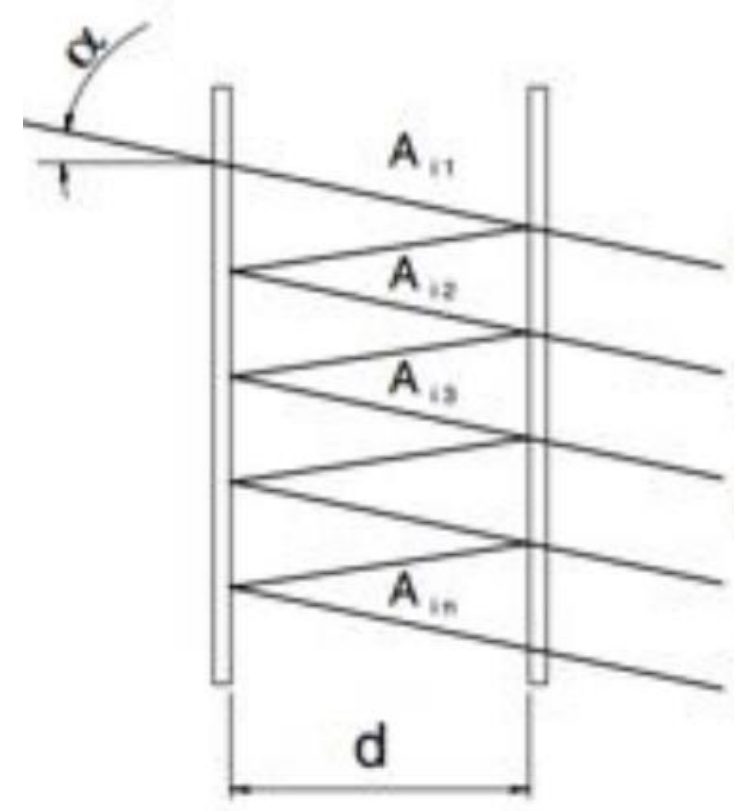

Figura 2.10 feixes refletidos em dois espelhos com distância "d"

Dependendo da fase dois feixes refletidos e transmitidos dentro da cavidade "d", a interferência pode ser maior o menor. Então se pode afirmar que, um feixe incidente cuja fase varia em função ao tempo é múltiplo do $\lambda / 2$, a interferência será construtiva [50].

$\mathrm{Na}$ seguinte equação mostra-se a diferença de fase $\delta$ entre dois raios sucessivos de comprimento de onda $\lambda$ :

$$
\delta=\frac{4 \pi n d \cos \theta}{\lambda}
$$

Onde " $n$ " é o índice de refração do meio, "d" o comprimento da cavidade e “ $\theta$ ” é o ângulo de incidência [50] . 
Tendo a refletância, se pode chegar a conhecer a fração transmitida da incidência inicial:

$$
\frac{I_{t}}{I_{0}}=\frac{(1-R)^{2}}{1+R^{2}-2 R \cos \delta}
$$

Onde R é o índice de reflexão. Para que a transmitância seja máxima:

$$
\cos \delta=1 \text { onde } \delta=2 \pi \mathrm{m} \text {, } \mathrm{m} \text { é um número inteiro }
$$

Juntando a equação (25) e (27) obtemos:

$$
\begin{gathered}
\delta=\frac{4 \pi n d}{\lambda} \rightarrow \delta=2 \pi m \\
c=v \lambda \rightarrow v=\frac{m c}{2 n d}
\end{gathered}
$$

Agora se define a $\Delta v$ como FSR (Free Spectral Range):

$$
\Delta v \equiv v_{m+1}-v_{m}=\frac{m c}{2 n d}
$$

O FSR representa a diferença de fase entre dois $\lambda$ para os quais a intensidade transmitida é máxima.

Agora definiremos o conceito de Finesse (F), que representa a medida da nitidez das franjas de interferência [50] .

$$
\mathrm{F}=\frac{4 R}{(1-R)^{2}}
$$

Com a equação (30) podemos reescrever a função $\frac{I_{t}}{I_{0}}$ e $\delta$ como [50]: 


$$
\begin{gathered}
\delta=\frac{4 \pi n d}{\lambda} \\
\mathrm{c}=v \lambda \rightarrow \delta=\frac{2 \pi v}{\Delta v} \\
\Delta v=\frac{c}{2 n d} \\
\frac{I_{t}}{I_{0}}=\frac{1}{1+F \sin ^{2}\left(\frac{\delta}{2}\right)}
\end{gathered}
$$

No experimento, foi mudando a distância de separação entre os dois lasers, fazendo que varie o valor $\delta$ pela dimensão da cavidade Fabry-Perot, mas a frequência portadora gerada pelos dois lasers é fixa.

Tomando em conta a equação (31) o espaço de frequência é dado pela seguinte equação:

$$
\Delta v=\frac{c}{2 d}
$$

Como a distância entre as duas antenas foram variáveis, a equação (33) podese reescrever da seguinte forma:

$$
d_{F}=\frac{c}{2 \Delta v}=\frac{\lambda}{2}
$$

Na equação (34) pode-se observar que as oscilações aparecem cada $\frac{\lambda}{2}$ do sinal EHF. 


\section{Desenvolvimento do Experimento}

O método utilizado para gerar ondas na banda EHF neste trabalho é baseado na geração por diferença de frequências, produzido pelo batimento de dois lasers, como mostrado na Figura 3.1. Um dos lasers tem seu comprimento de onda fixo, mas é modulado externamente em amplitude; o comprimento de onda do segundo laser varia em relação ao primeiro com passos (em frequência) de 100 em $100 \mathrm{GHz}$ até $400 \mathrm{GHz}$. Os lasers som combinados por um power combiner e logo amplificados por um EDFA (Erbium Doped Fiber Amplifier). Um atenuador variável, VOA 2 (Variable Optical Attenuattor), é usado para limitar a potência óptica do feixe em 30mW (valor máximo permitido pela antena transmissora). O feixe alimenta assim a antena na qual se produz o batimento dos lasers, gerando uma portadora em alta frequência modulada por um sinal. Para a detecção do sinal na banda EHF utilizou-se detectores Schoktty de alta sensibilidade.

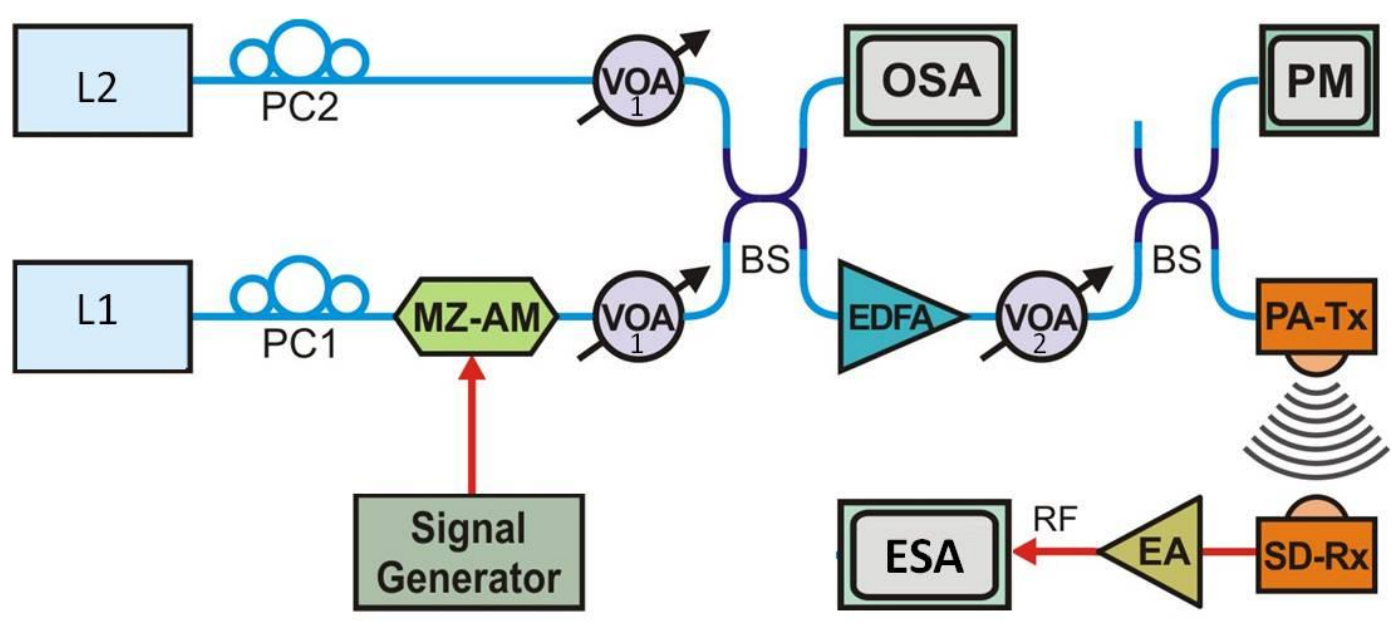

Figura 3.1: Configuração do experimento para a geração e detecção de ondas na banda EHF.

\subsection{Geração de altas frequências na banda EHF}

Considerando a equação (8) e a configuração utilizada para gerar altas frequências (descrita na seção 3.2), foi utilizado um laser (Clarity Wavelenght References [51]) de comprimento de onda fixa em $1550.51 \mathrm{~nm}$ representado como 
L1 na Figura 3.1, e um laser L2 (New Focus Tunable Laser Controller [52]), o qual muda de comprimento de onda para conseguir as portadoras desejadas na banda EHF.

Neste experimento obtiveram-se frequências portadoras desde $100 \mathrm{GHz}$ até. $400 \mathrm{GHz}$, . Na seguinte tabela mostram-se os comprimentos de ondas necessários no L2 para obter as frequências.

Tabela 3.1: Comprimentos de ondas resultantes para gerar frequências separadas por $100 \mathrm{GHz}$.

\begin{tabular}{|c|c|c|}
\hline L1 $(\mathrm{nm})$ & $\mathrm{L} 2(\mathrm{~nm})$ & $v_{1}-v_{2}(\mathrm{GHz})$ \\
\hline 1550,51546 & 1550,51546 & 0 \\
\hline 1550,51546 & 1551,31724 & 100 \\
\hline 1550,51546 & 1552,119851 & 200 \\
\hline 1550,51546 & 1552,923292 & 300 \\
\hline 1550,51546 & 1553,727565 & 400 \\
\hline
\end{tabular}

Na Tabela 3.1, pode-se observar que cada comprimento de onda do L2 é maior do que L1, em múltiplos de $0,8 \mathrm{~nm}$, dando como resultado um espectro de diferença de 100 em $100 \mathrm{GHz}$.

Para confirmar os valores o sinal foi medido, depois do EDFA, usando um analisador de espectro óptico (OSA Anritsu [53]).

Na Figura 3.2 mostram-se os comprimentos de ondas dos lasers depois de calibrar o OSA, e igualar os valores das potências. 


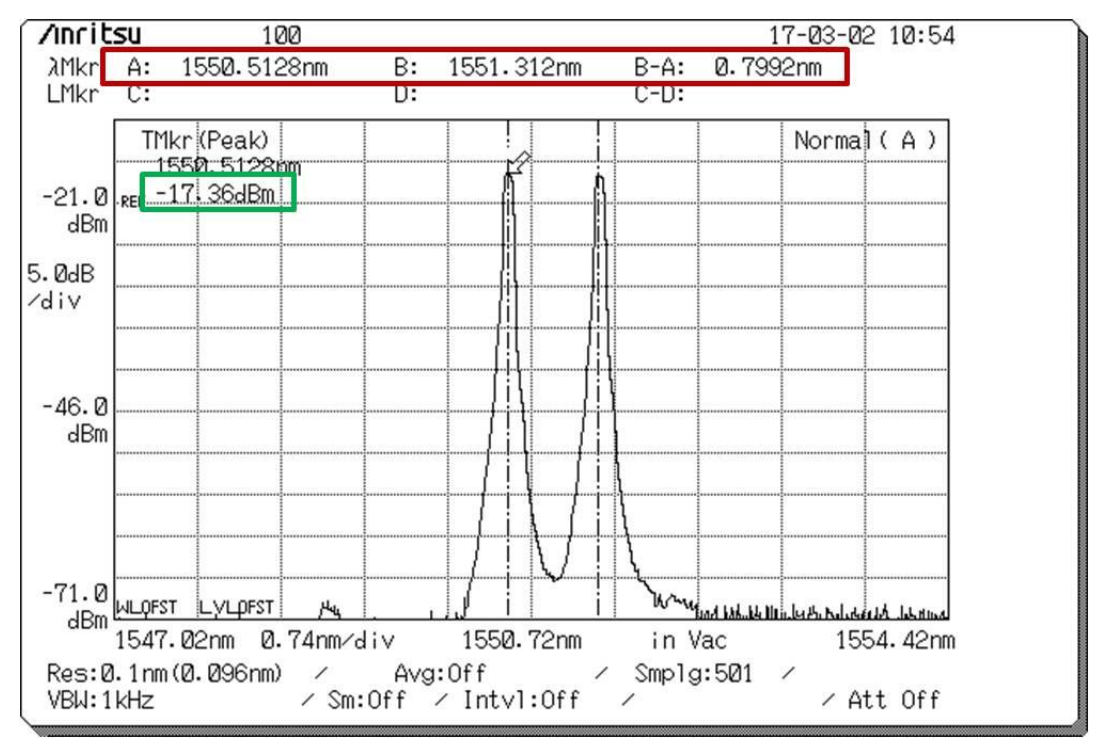

Figura 3.2: Comprimento de onda do L1 em 1550,5128 nm (Mkr A) e do L2 em 1551,312 nm (Mkr B), cuja diferença é de 0,7992 nm (Mkr B-A). A potência óptica dos dois lasers é de $-17.36 \mathrm{dBm}$.

Ao configurar o segundo laser com os comprimentos de ondas muito próximos aos mostrado na Tabela 3.1, se obtém os gráficos mostrados na Figura 3.3, o qual mostra as diferentes frequências formadas pela diferença dos comprimentos de onda dos lasers.

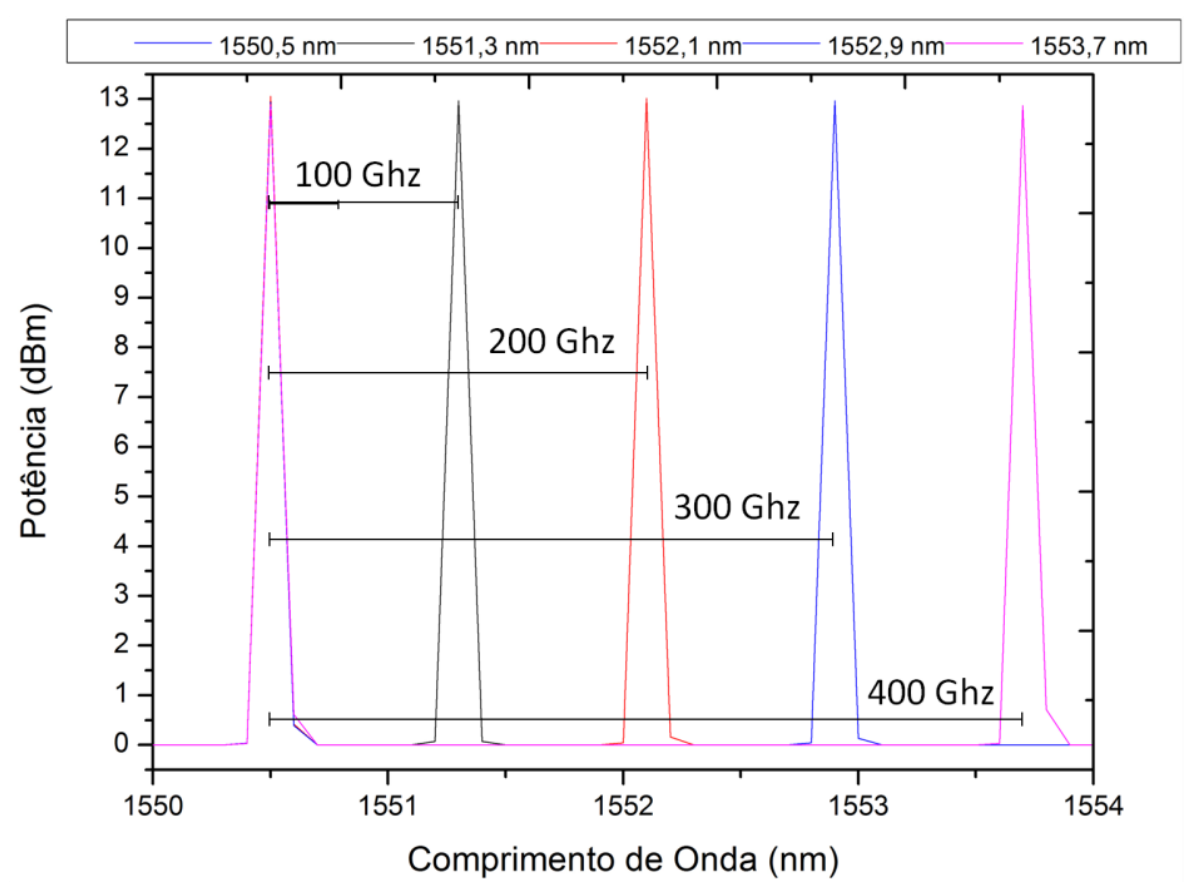

Figura 3.3: Medidas do OSA dos comprimentos de ondas nas diferentes frequências portadoras. 


\subsection{Caracterização da antena Schottky de banda larga}

Como mostrado na Figura 3.1, existem dois controladores de polarização (PC1 e PC2), um para cada laser. O PC1 é usado para alinhar o laser L1 ao modulador de amplitude (AM) e o PC2 é usado para garantir que os dois feixes estejam na mesma polarização na entrada da antena.

Uma vez igualadas as potências dos lasers, elas são medidas no Power Meter e no OSA (na saída do segundo power splitter) antes de serem conectadas à antena, como medida de segurança. Logo de verificar os valores desejados a antena é conectada para gerar ondas em EHF.

As ondas geradas pelo transmissor são detectadas pela Antena Schottky de alta frequência. Um amplificador é usado para amplificar o sinal detectado.

Por outro lado, é essencial também a caracterização do modulador de amplitude. A caracterização do modulador AM (Covega Mach-40 [54]) usado no experimento é apresentado na Figura 3.4

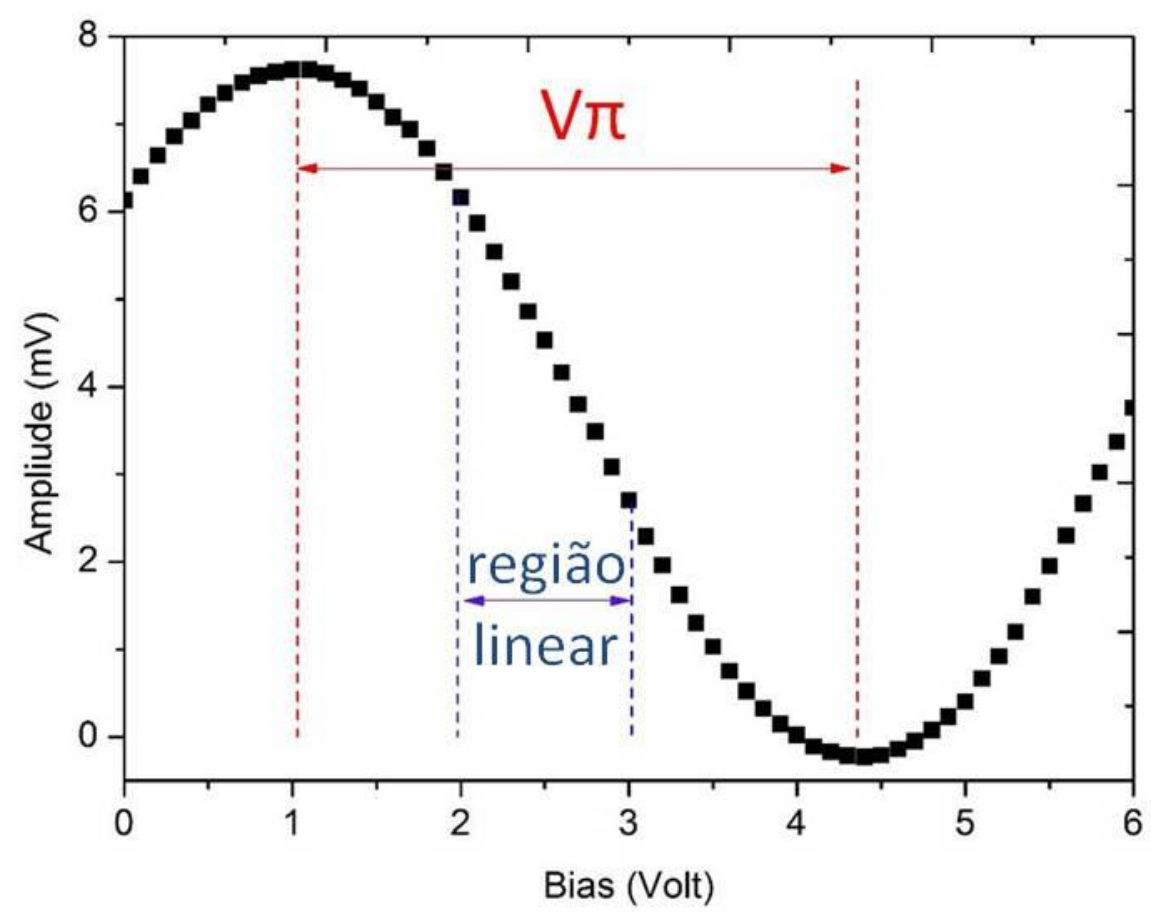

Figura 3.4: Caracterização do modulador de amplitude variando o BIAS com uma fonte DC. 
Na Figura 3.4 mostra (traço vermelho) que o valor da tensão de polarização para produzir a máxima transmissão da luz no modulador é de $1 \mathrm{~V}$ e o valor que produz a extinção é em 4,4 V.

\subsubsection{Resposta da Antena variando a frequência de modulação}

Para avaliar a resposta da antena à variação da frequência de modulação foi usado um gerador de sinais (Anritsu [55]) conectado ao modulador de amplitude. $\mathrm{O}$ sinal de modulação foi uma onda senoidal com amplitude $\mathrm{Vpp}=1 \mathrm{~V}$, e as frequências de modulação foram de $500 \mathrm{MHz}, 1 \mathrm{GHz}, 1.5 \mathrm{GHz}, 2 \mathrm{GHz}, 2.5 \mathrm{GHz}$, $3 \mathrm{GHz}, 3.5 \mathrm{GHz}$ e $4 \mathrm{GHz}$.

A distância entre as antenas para a aquisição dos dados foi de $7 \mathrm{~mm}$ para todas as frequências portadoras. Essa distância foi escolhida porque experimentalmente foi observado que a resposta da antena receptora foi melhor.

Mantendo a distância fixa, mediram-se os valores com a antena transmissora emitindo o sinal na banda EHF (antena com potência óptica) e sem emitir o sinal (sem potência óptica chegando à antena Tx) para ter uma ideia das diferenças de potências entre o sinal e o ruído para as diferentes frequências de portadora em diferentes frequências de modulação.

Um analisador de espectro elétrico (ESA Anritsu [56]) foi utilizado para obter os dados da antena receptora Schottky (ACST [57]), mas os sinais detectados pela antena foram muito baixos, quase irreconhecíveis no analisador de espectro; assim foi necessário usar um amplificador de rádio frequência (Mini-Circuits [58]), obtendo os resultados nas diferentes bandas de frequências, como mostrado nas Tabela 3.2 até a Tabela 3.5. 
Tabela 3.2: Potência do sinal detectado na antena Rx em $100 \mathrm{GHz}$ de portadora.

\begin{tabular}{|c|c|c|c|}
\hline \multicolumn{5}{|c|}{$100 \mathrm{GHz}$ de portadora } \\
\hline $\begin{array}{c}\text { Frequência de } \\
\text { modulação } \\
(\mathrm{GHz})\end{array}$ & $\begin{array}{c}\text { Potência do } \\
\text { ruído }(\mathrm{dBm})\end{array}$ & $\begin{array}{c}\text { Potência na } \\
\text { antena Rx } \\
(\mathrm{dBm})\end{array}$ & $\begin{array}{c}\text { Sinal/ ruído } \\
(\mathrm{dB})\end{array}$ \\
\hline 0,5 & $-80,37$ & $-50,96$ & 29,41 \\
\hline 1 & $-74,08$ & $-52,89$ & 21,19 \\
\hline 1,5 & $-83,74$ & $-51,72$ & 32,02 \\
\hline 2 & $-81,82$ & $-49,6$ & 30,1 \\
\hline 2,5 & $-87,57$ & $-55,42$ & 32,15 \\
\hline 3 & $-91,06$ & $-56,16$ & 34,09 \\
\hline 3,5 & $-86,12$ & $-56,33$ & 29,79 \\
\hline 4 & $-94,21$ & $-64,34$ & 29,87 \\
\hline
\end{tabular}

Tabela 3.3: Potência do sinal detectado na antena Rx em $200 \mathrm{GHz}$ de portadora.

\begin{tabular}{|c|c|c|c|}
\hline \multicolumn{4}{|c|}{$200 \mathrm{GHz}$ de portadora } \\
\hline $\begin{array}{c}\text { Frequência de } \\
\text { modulação } \\
(\mathrm{GHz})\end{array}$ & $\begin{array}{c}\text { Potência do } \\
\text { ruído }(\mathrm{dBm})\end{array}$ & $\begin{array}{c}\text { Potência na } \\
\text { antena Rx } \\
(\mathrm{dBm})\end{array}$ & $\begin{array}{c}\text { Sinal/ ruído } \\
(\mathrm{dB})\end{array}$ \\
\hline 0,5 & $-81,43$ & $-64,17$ & 17,26 \\
\hline 1 & $-73,43$ & $-65,61$ & 7,82 \\
\hline 1,5 & $-82,3$ & $-63,74$ & 18,56 \\
\hline 2 & $-82,21$ & $-65,9$ & 16,31 \\
\hline 2,5 & $-86,07$ & -66 & 20,07 \\
\hline 3 & $-91,32$ & $-65,04$ & 26,28 \\
\hline 3,5 & $-84,23$ & $-63,17$ & 21,06 \\
\hline 4 & $-94,9$ & $-71,14$ & 23,76 \\
\hline
\end{tabular}

Tabela 3.4: Potência do sinal detectado na antena Rx em $300 \mathrm{GHz}$ de portadora.

\begin{tabular}{|c|c|c|c|}
\hline \multicolumn{4}{|c|}{$300 \mathrm{GHz}$ de portadora } \\
\hline $\begin{array}{c}\text { Frequência de } \\
\text { modulação } \\
(\mathrm{GHz})\end{array}$ & $\begin{array}{c}\text { Potência do } \\
\text { ruído }(\mathrm{dBm})\end{array}$ & $\begin{array}{c}\text { Potência na } \\
\text { antena Rx } \\
(\mathrm{dBm})\end{array}$ & $\begin{array}{c}\text { Sinal/ ruído } \\
(\mathrm{dB})\end{array}$ \\
\hline 0,5 & $-82,2$ & $-68,84$ & 13,36 \\
\hline 1 & $-73,36$ & $-68,65$ & 4,71 \\
\hline 1,5 & $-80,37$ & $-72,41$ & 7,96 \\
\hline 2 & $-78,52$ & $-73,06$ & 5,46 \\
\hline 2,5 & $-86,52$ & $-70,58$ & 15,94 \\
\hline 3 & $-91,24$ & $-68,51$ & 22,73 \\
\hline 3,5 & $-83,24$ & $-65,77$ & 17,47 \\
\hline 4 & $-93,39$ & $-73,26$ & 20,13 \\
\hline
\end{tabular}


Tabela 3.5: Potência do sinal detectado na antena Rx em $400 \mathrm{GHz}$ de portadora.

\begin{tabular}{|c|c|c|c|}
\hline \multicolumn{4}{|c|}{$400 \mathrm{GHz}$ de portadora } \\
\hline $\begin{array}{c}\text { Frequência de } \\
\text { modulação } \\
(\mathrm{GHz})\end{array}$ & $\begin{array}{c}\text { Potência do } \\
\text { ruído }(\mathrm{dBm})\end{array}$ & $\begin{array}{c}\text { Potência na } \\
\text { antena Rx } \\
(\mathrm{dBm})\end{array}$ & $\begin{array}{c}\text { Sinal/ ruído } \\
(\mathrm{dB})\end{array}$ \\
\hline 0,5 & $-82,39$ & $-74,62$ & 7,77 \\
\hline 1 & $-72,89$ & $-68,4$ & 4,49 \\
\hline 1,5 & $-80,2$ & $-75,7$ & 4,5 \\
\hline 2 & $-84,24$ & $-73,46$ & 10,78 \\
\hline 2,5 & $-86,63$ & $-72,84$ & 13,79 \\
\hline 3 & $-91,05$ & $-70,36$ & 20,69 \\
\hline 3,5 & $-84,04$ & $-66,62$ & 17,42 \\
\hline 4 & $-91,74$ & $-74,1$ & 17,64 \\
\hline
\end{tabular}

Em cada tabela mostrada, é possível apreciar que a potência diminui enquanto a frequência de portadora cresce. Isso pode ser observado na Figura 3.5:

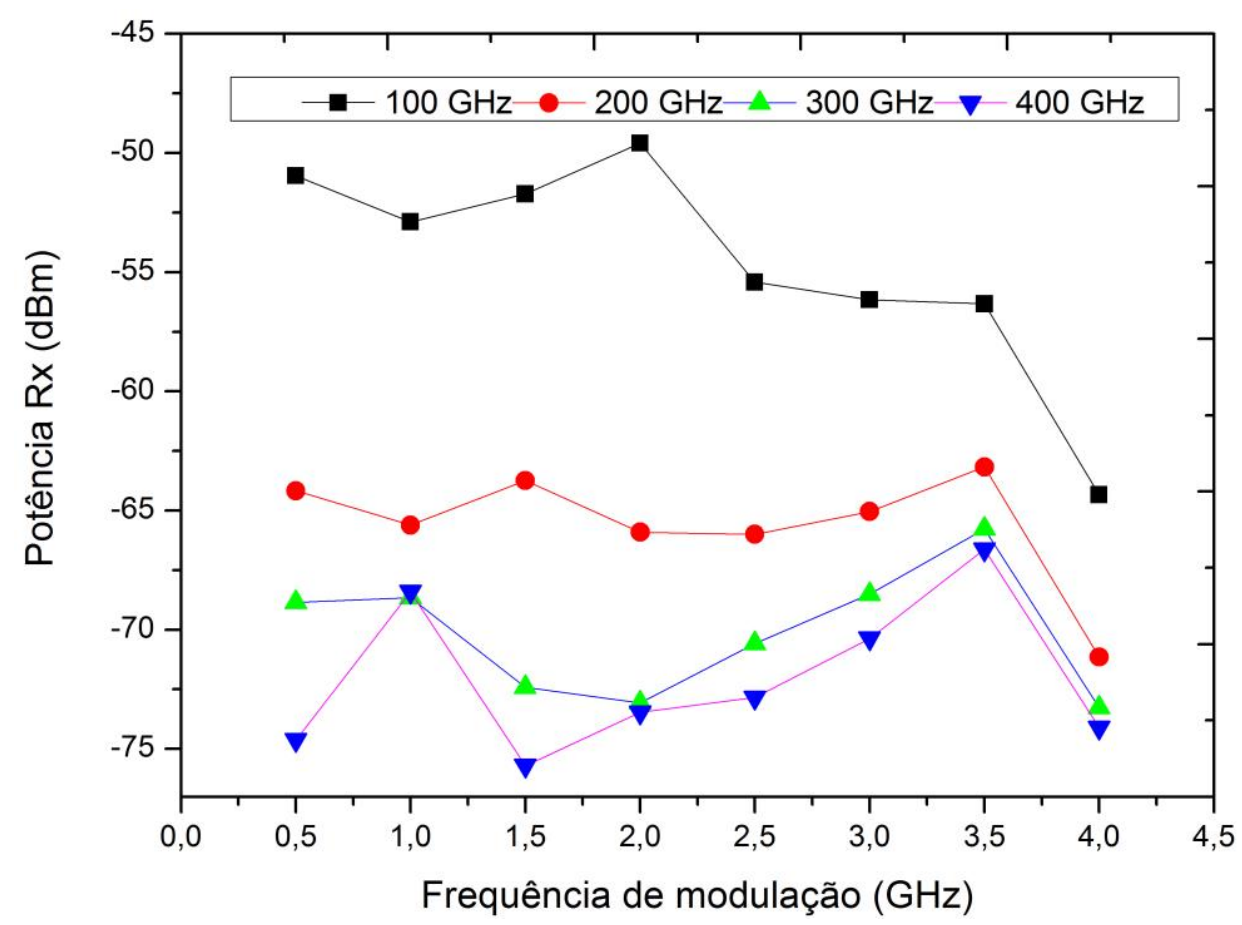

Figura 3.5: Comparação das potências das diferentes frequências portadoras.

Na Figura 3.6 pode se observar que a relação sinal ruído também diminui enquanto a frequência da portadora cresce. 


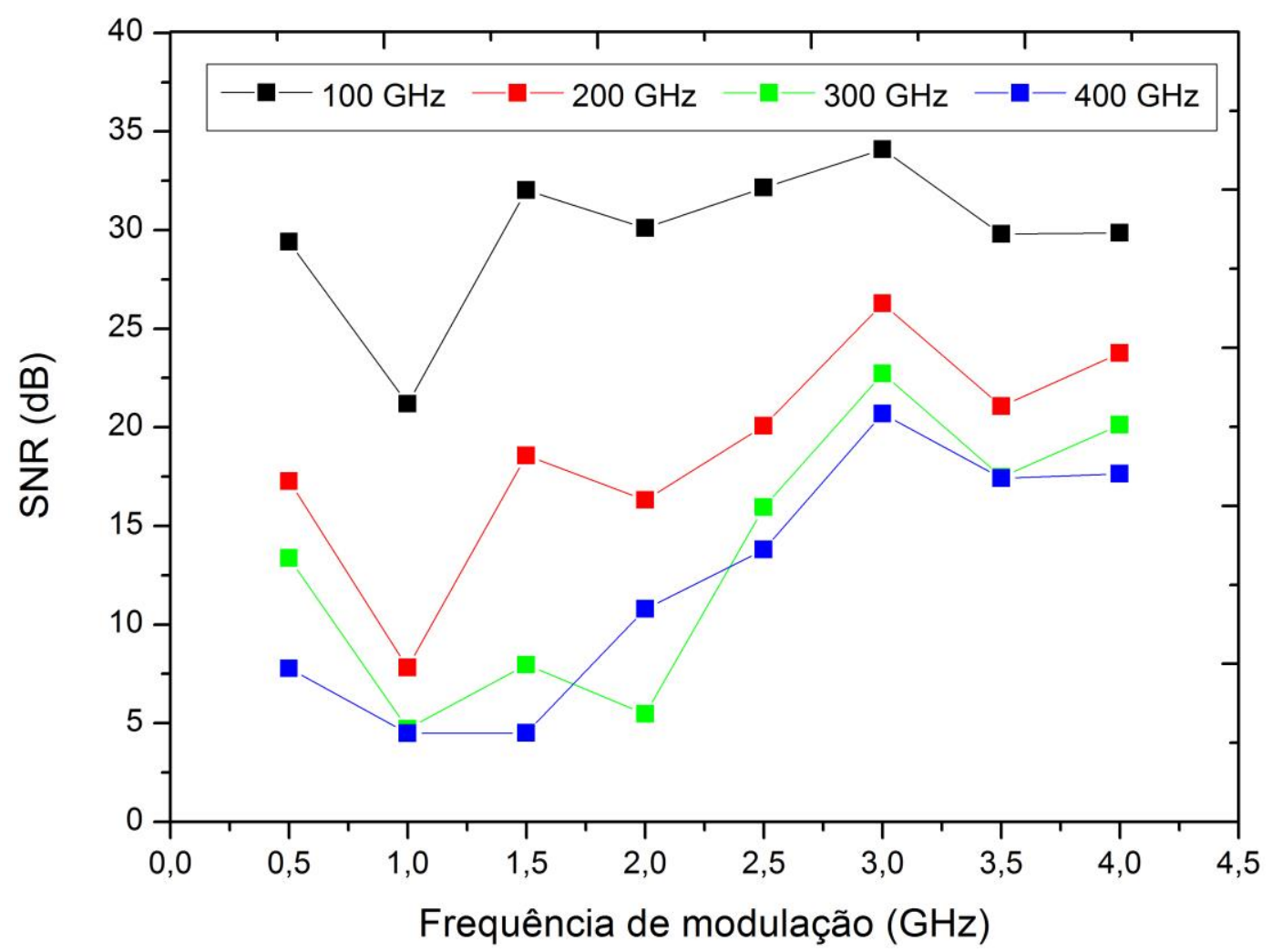

Figura 3.6: Comparação da Relação sinal/ruído das tabelas 3.3 até 3.5.

Quando o SNR das Tabela 3.2 até a Tabela 3.5 são mostradas num mesmo gráfico, pode-se observar que a frequências de modulação no espectro dos lasers de $100 \mathrm{GHz}$ está mais longe do ruído ao ter um SNR maior que nas outras frequências.

\subsubsection{Resposta da Antena variando a distância entre Tx e Rx}

A potência do ruído também foi considerada nas tabelas anteriores, devido a que os valores de ruído para cada frequência de modulação mudavam, por isso para testar a resposta da antena à variação da distância foram selecionadas as faixas de frequências onde as potências dos sinais estão mais longe da potência do ruído.

Depois de verificar as melhores frequências de portadoras para trabalhar (e variando também a frequência de modulação), foi feito a análise do mesmo sinal em função da distância entre as antenas. A variação da distância foi feita com passos de $100 \mu \mathrm{m}$, a Figura 3.7 mostra o resultado deste teste, onde foram adquiridos 1100 
passos, cobrindo assim uma distância total de $11.0 \mathrm{~cm}$, para uma frequência portadora de $100 \mathrm{GHz}$.

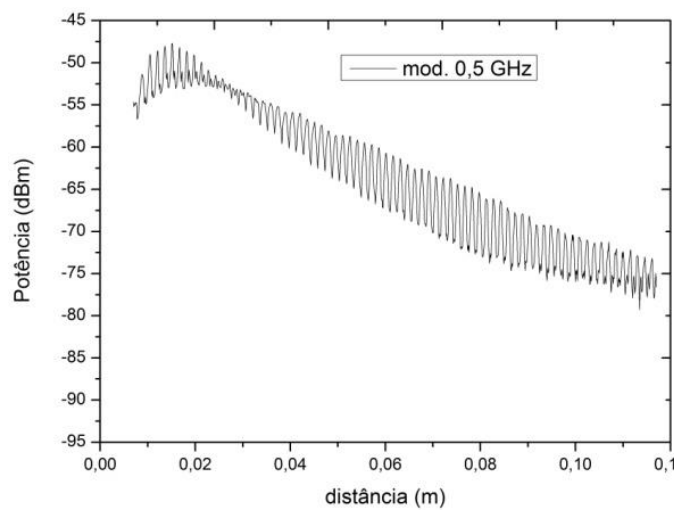

(a)

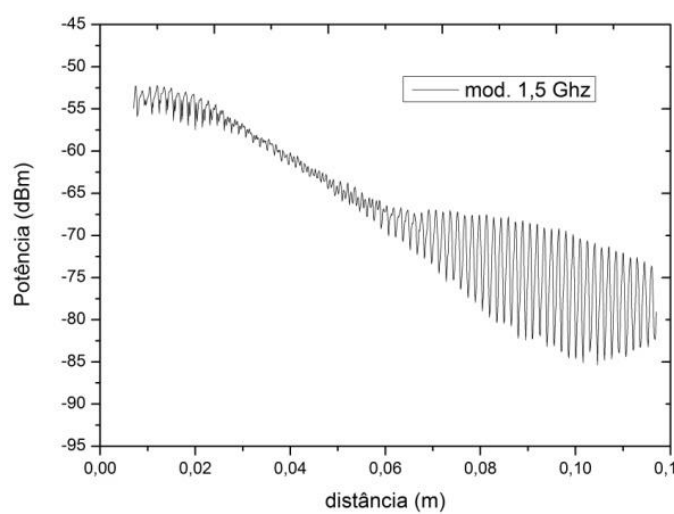

(c)

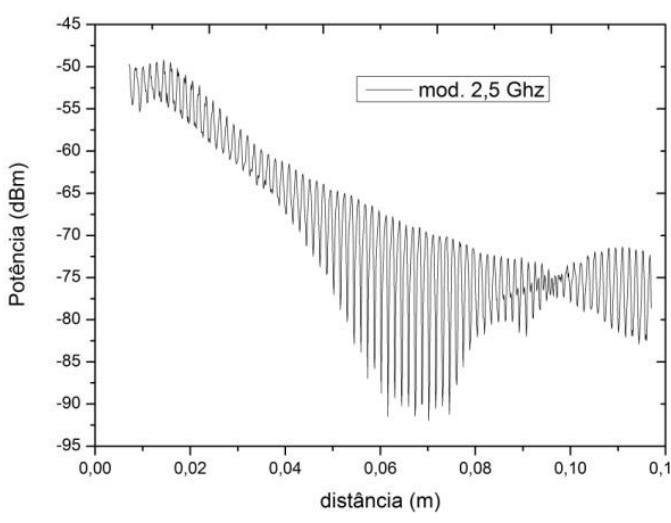

(e)

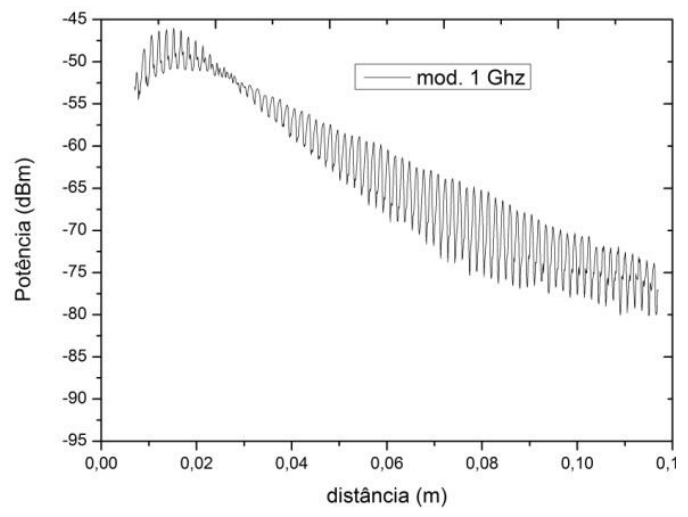

(b)

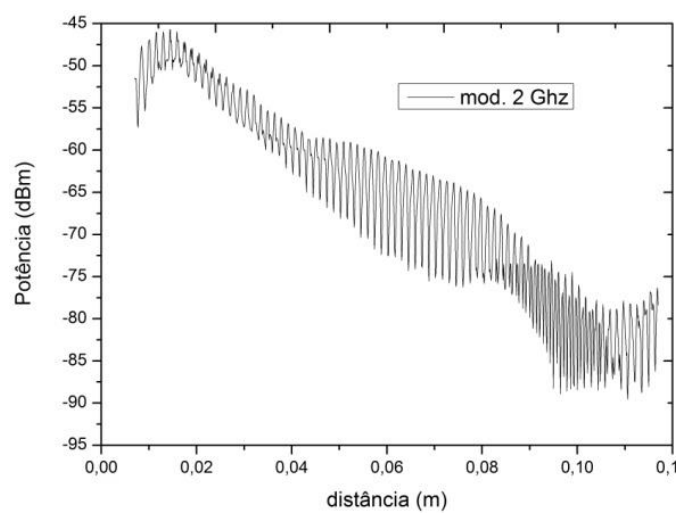

(d)

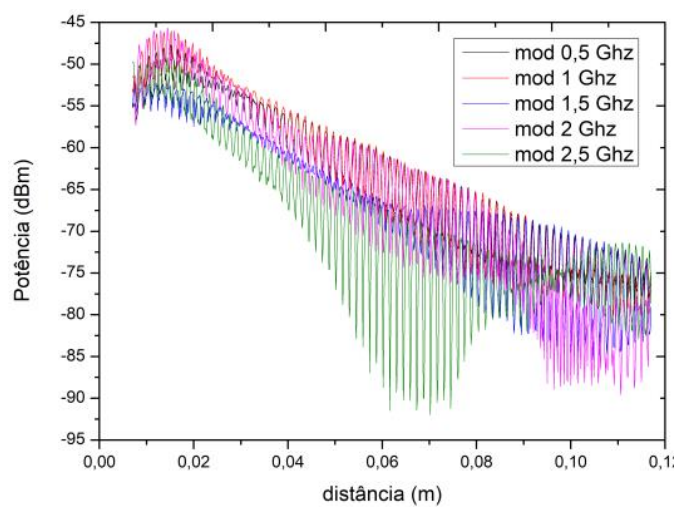

(f)

Figura 3.7: Resposta da Antena para uma portadora de $100 \mathrm{GHz}$ em função da distância. (a), (b), (c), (d) e (e) para diferentes frequências de modulação; (f) todas as medidas juntas. 
Pelo mesmo conceito do interferômetro Fabry-Perot (explicado na sessão 2.7), as antenas ao ir mudando de distância, tem interferências construtivas e destrutivas, como se pode observar na Figura 3.7.

As duas antenas (Tx e Rx) atuam como os espelhos num interferômetro Fabry-Perot e a separação delas forma uma cavidade onde ocorre a transmitância e refletância. No experimento, alinharam-se as antenas manualmente, tentando que esteja o mais paralelamente possível para obter uma boa leitura na parte da recepção, fazendo que tenha o mesmo efeito que mostra a Figura 2.10.

Nos primeiros centímetros de separação entre as antenas se tem muita refletância devido à pequena cavidade que tem as antenas. Nas distâncias posteriores a 5 centímetros aproximadamente, as reflexões são menores por que a distância da cavidade é maior, obtendo assim, um sinal mais uniforme a medida que a distância vai sendo maior.

Também se tem que considerar o comprimento de onda da frequência portadora já que, como foram mostradas na equação (39), as oscilações aparecem cada deslocamento da antena de $\lambda / 2$.

Nos últimos centímetros que percorre a antena $\mathrm{Rx}$, tem-se que considerar também o nível de ruído que foi mostrado nas Tabela 3.2 até a Tabela 3.5, por que também influem na variação do sinal.

Na Figura 3.8 é mostrada a resposta da antena para uma frequência de 200 $\mathrm{GHz}$ variando a distância e frequência de modulação. 


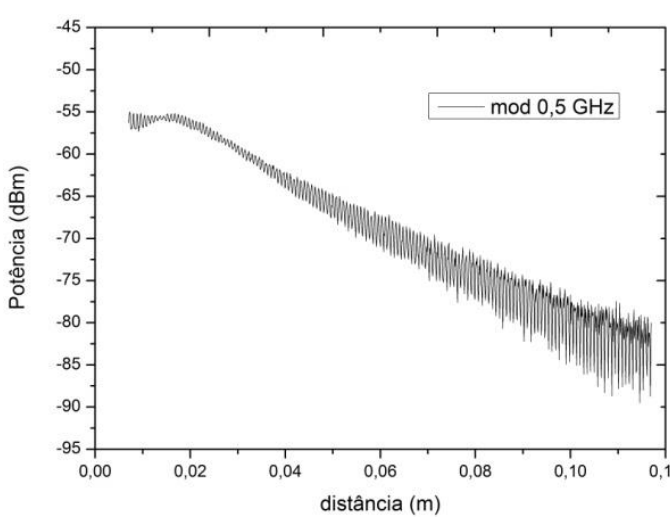

(a)

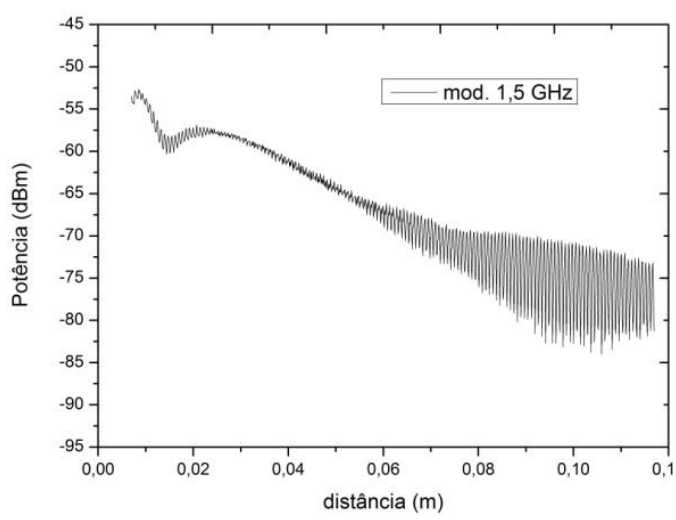

(c)

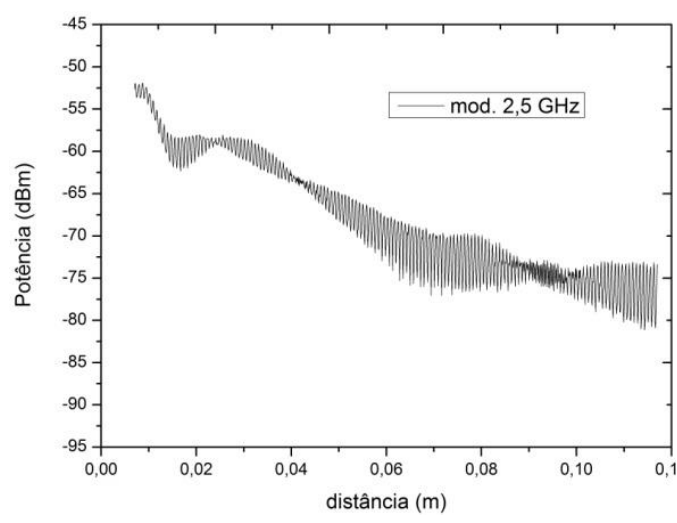

(e)

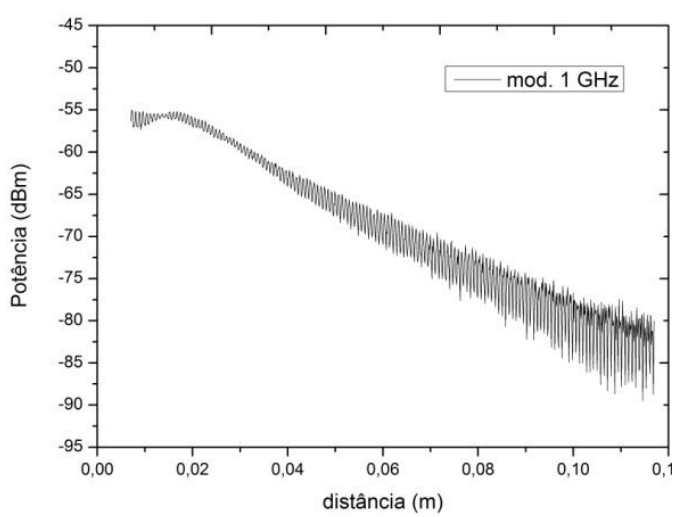

(b)

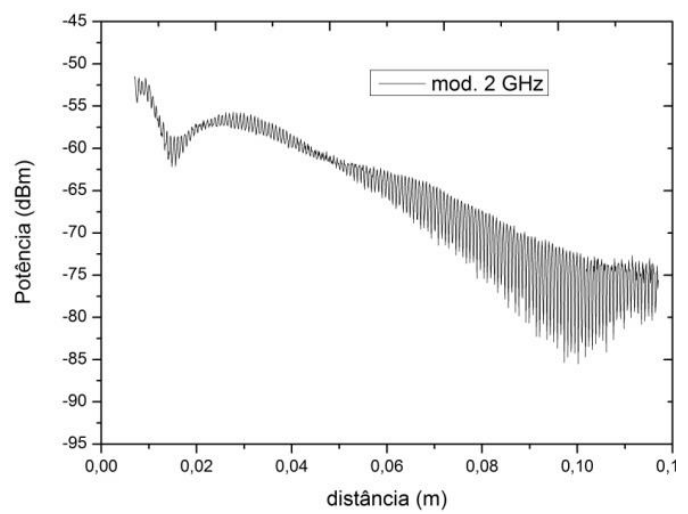

(d)

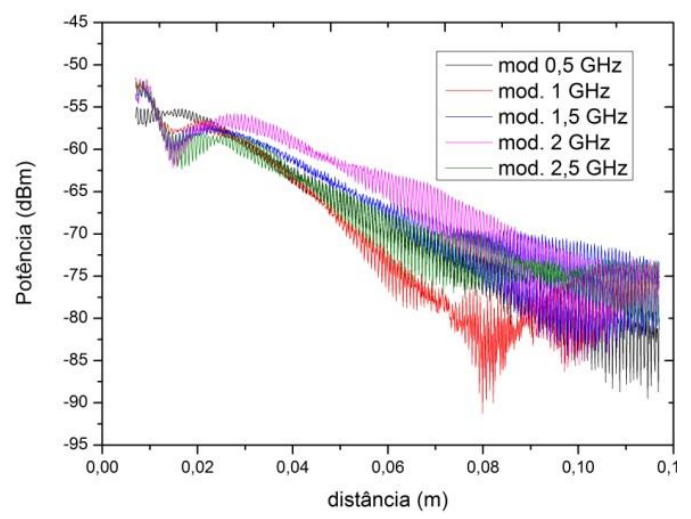

(f)

Figura 3.8: Resposta da Antena para uma portadora de $200 \mathrm{GHz}$ em função da distância. (a), (b), (c), (d) e (e) para diferentes frequências de modulação; (f) todas as medidas juntas.

O nível de potência de detecção diminui na medida em que a frequência da portadora aumenta; por conseguinte, só foram feitas medições até os $300 \mathrm{GHz}$ do espectro da banda EHF. 


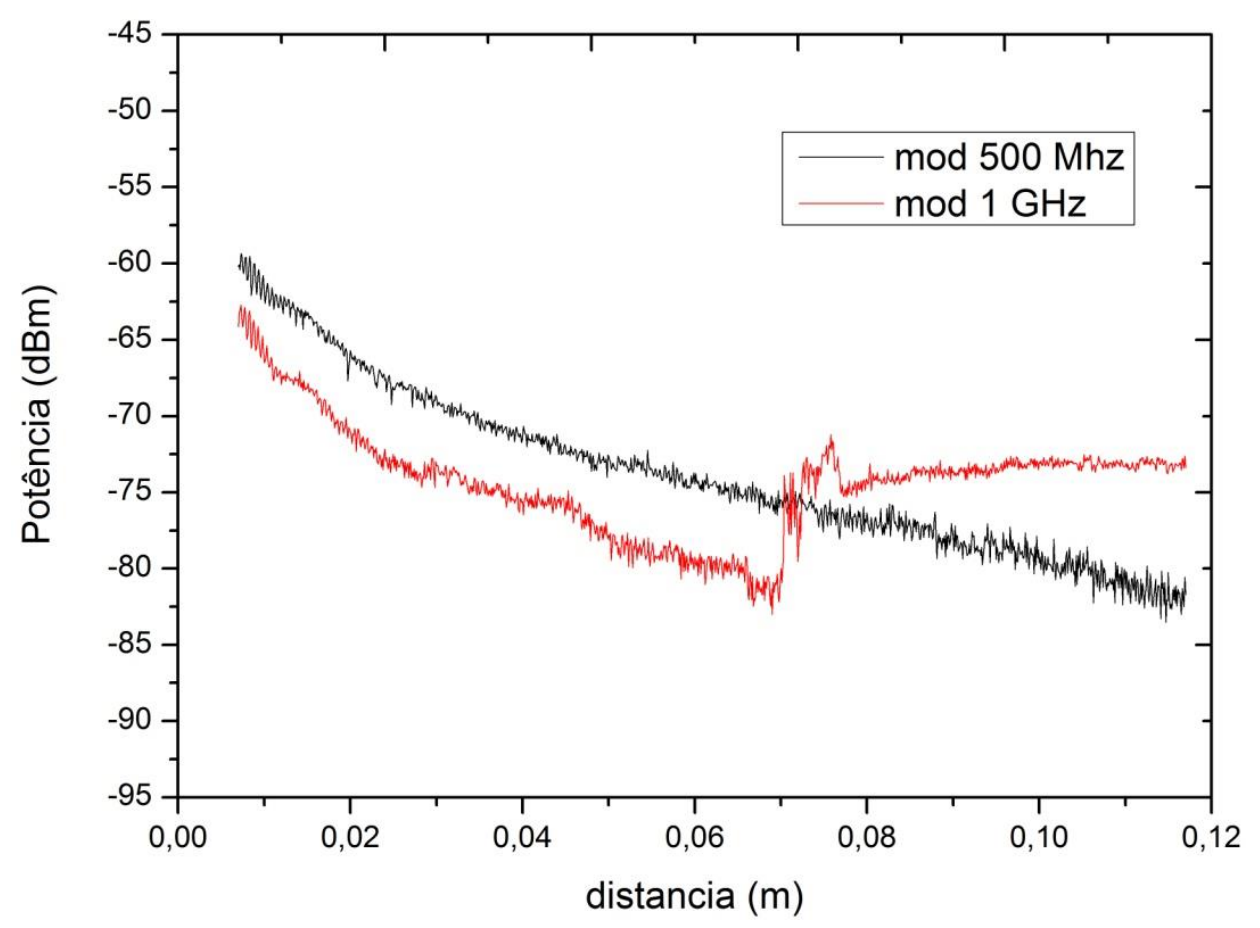

Figura 3.9: Resposta da Antena para uma frequência portadora de $300 \mathrm{GHz}$ em função da distância até $11 \mathrm{~cm}$ com diferentes frequências de modulação.

\subsection{Caracterização da Antena Schottky de banda estreita}

Na Figura 3.10 é mostrada a configuração para a caracterização da antena de recepção de baixa frequência. Se comparado à configuração da Figura 3.1, esta configuração usa um gerador de sinais vectoriais VSG (Vector Signal Generator, Anritsu [59]),) e um analisador de sinais vectoriais VSA (Vector Signal Analyzer VSA Anritsu [60]). Foi também incluído um mixer de radiofrequência (MiniCircuits [61]) conjuntamente com um gerador de funções (Agilent Technologies [62]). A inclusão do mixer permite levar a frequência do sinal detectado para uma frequência maior na qual o VSA consegue trabalhar. Finalmente, a antena receptora foi trocada por uma de baixa frequência, mas com alta sensibilidade, do mesmo fabricante (Schottky 2DL 12C LS 2500 A1 ACST). 


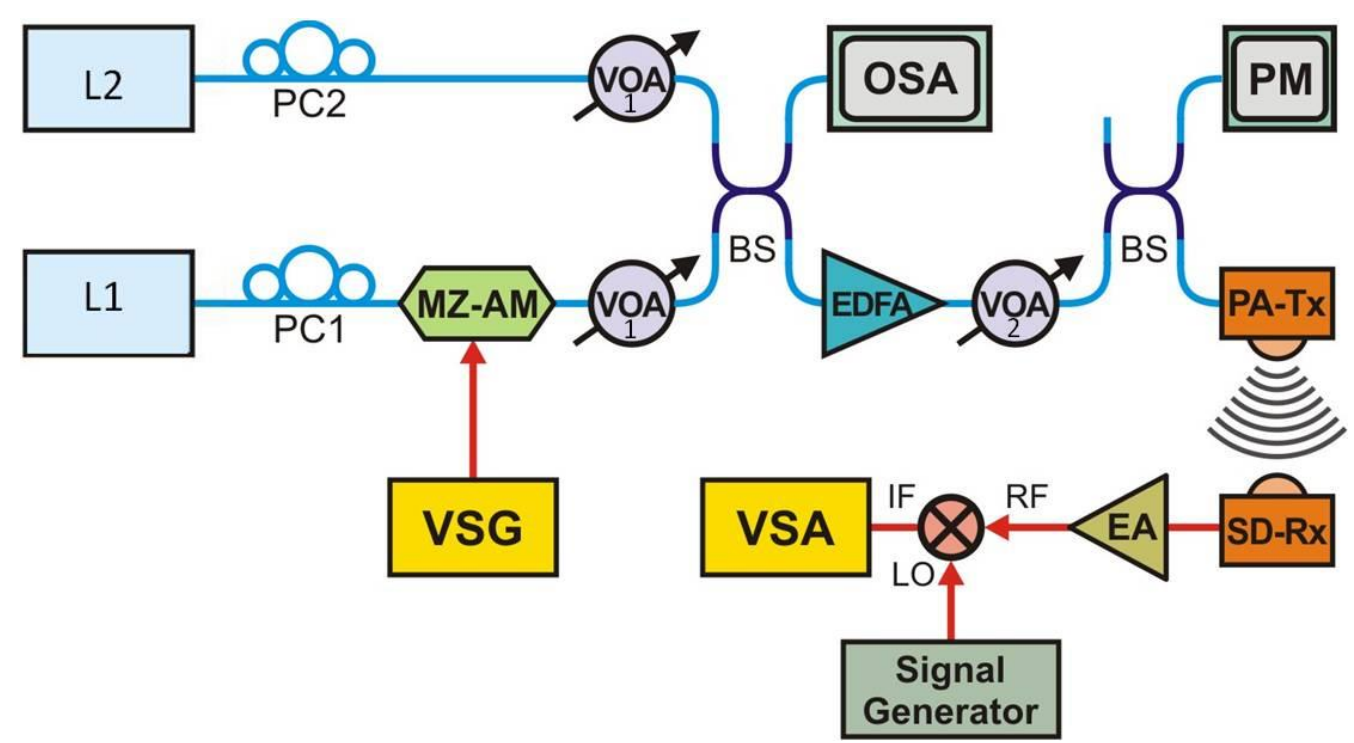

Figura 3.10: Configuração no laboratório para gerar e detectar ondas no espectro EHF com uma antena receptora de baixa frequência.

\subsubsection{Resposta da antena de baixa frequência variando a frequência portadora}

Devido a que a largura de banda elétrica da nova antena é de baixa frequência, o VSG foi configurado para gerar um sinal senoidal de $2 \mathrm{MHz}$ de frequência com $\mathrm{Vpp}=1 \mathrm{~V}$. Na detecção utilizou-se um amplificador de rádio frequência de baixo ruído (MITEQ [[63]); o sinal detectado assim foi misturado com um sinal de 29 $\mathrm{MHz}$, levando a frequência do sinal detectado até $31 \mathrm{MHz}$, já que a frequência mínima de trabalho do VSA, segundo a suas especificações, é de $30 \mathrm{MHz}$.

Na seguinte tabela mostram-se a resposta da antena de baixa frequência com a nova configuração, variando a frequência de portadora de $100 \mathrm{GHz}$ até $500 \mathrm{GHz}$, para uma frequência de modulação de $2 \mathrm{MHz}$, e uma distância entre as antenas de $12.9 \mathrm{~mm}$. 
Tabela 3.6: Resposta da antena de baixa frequência para diferentes frequências portadoras.

\begin{tabular}{|c|c|c|c|}
\hline $\begin{array}{c}\text { Frequência. de } \\
\text { portadora. } \\
(\mathrm{GHz})\end{array}$ & $\begin{array}{c}\text { Potência do } \\
\text { ruído }(\mathrm{dBm})\end{array}$ & $\begin{array}{c}\text { Potência na } \\
\text { antena } \mathrm{Rx} \\
(\mathrm{dBm})\end{array}$ & $\begin{array}{c}\text { Sinal / ruído } \\
(\mathrm{dB})\end{array}$ \\
\hline 100 & $-48,12$ & $-4,96$ & 43,16 \\
\hline 200 & $-48,32$ & $-14,99$ & 33,33 \\
\hline 300 & $-48,74$ & $-33,72$ & 15,02 \\
\hline 400 & $-48,59$ & $-42,6$ & 5,99 \\
\hline
\end{tabular}

$\mathrm{Na}$ Tabela 3.6 pode-se observar que a antena tem uma melhor resposta na frequência de $100 \mathrm{GHz}$, na qual o nível da potência do sinal está pouco mais de 43 dB acima do nível de ruído, no caso de $200 \mathrm{GHz}$ se tem uma potência de $33 \mathrm{~dB}$ acima do ruído; tendo em consideração que o ruído fica num valor aproximado de $-48 \mathrm{dBm}$. Assim estas frequências são as melhores opções para poder transmitir informação; a Figura 3.11 apresenta o valor da relação SNR em função da frequência portadora, para uma modulação de $2 \mathrm{MHz}$.

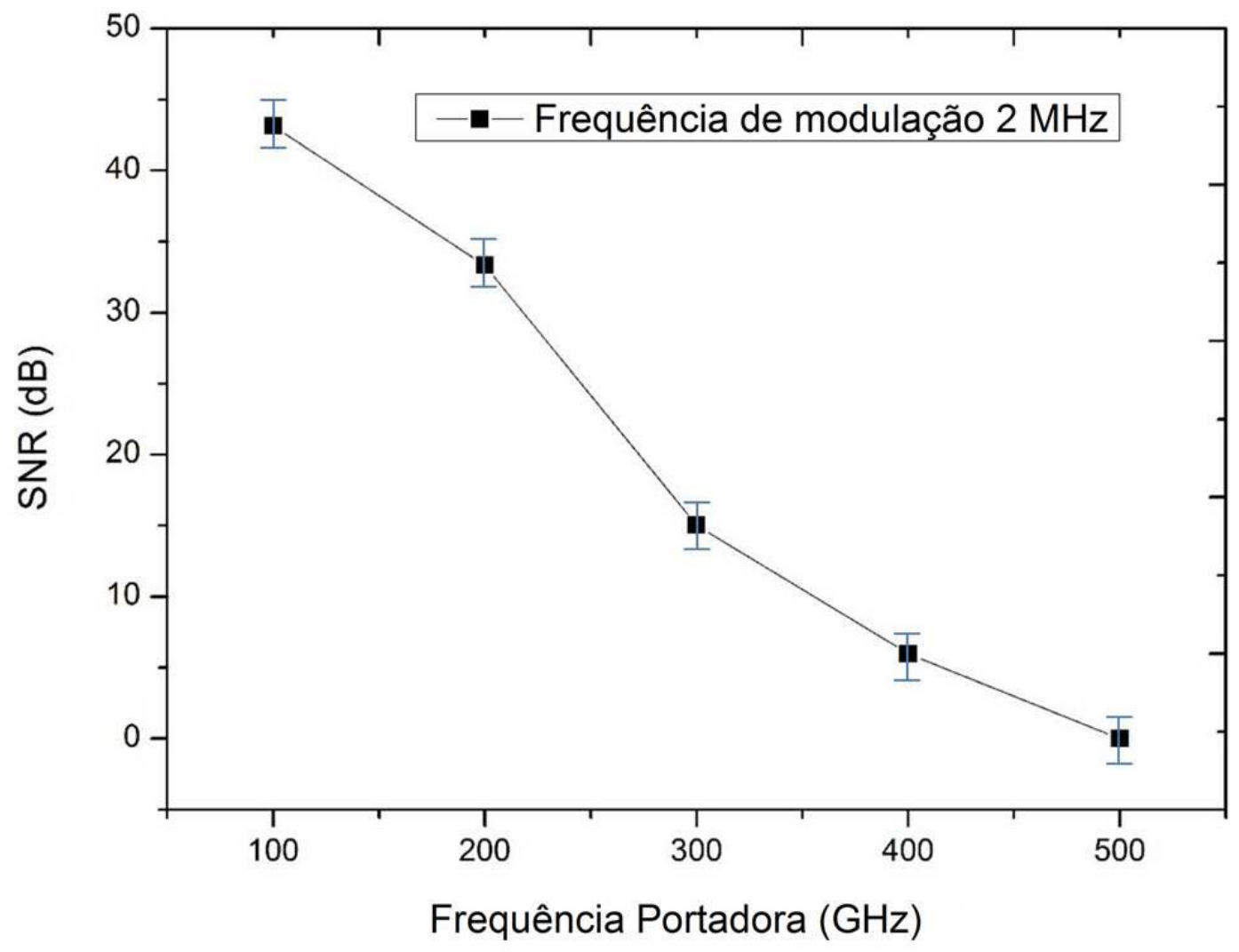

Figura 3.11: Sinal sobre o ruído com relação à frequência portadora. 
Como as antenas estavam muito próximas uma da outras, havia a preocupação de que as antenas se acoplassem mutuamente perto da energia reativa do campo, as distâncias dos campos próximos foram calculadas e são mostradas na Tabela 3.7 onde se mostra que para todas as frequências portadoras obtidas, $5 \mathrm{~mm}$ de separação é pelo menos 10 vezes a distância do limite do campo próximo.

Tabela 3.7 Campo Próximo para os comprimentos de onda de 100, 200 e 300 $\mathrm{GHz}$.

\begin{tabular}{|c|c|c|c|c|}
\hline $\begin{array}{c}\text { Frequência } \\
\text { portadora }\end{array}$ & $\begin{array}{c}\text { Compriment } \\
\text { o de onda } \mathrm{h}\end{array}$ & $\begin{array}{c}\text { Limite do } \\
\text { campo próximo } \\
\frac{\lambda}{2 \pi}\end{array}$ & $\begin{array}{c}\text { Comprimento } \\
\text { de onda } 5 \mathrm{~mm}\end{array}$ & $\begin{array}{c}\text { Comprimento } \\
\text { de onda } 15 \mathrm{~mm}\end{array}$ \\
\hline $100 \mathrm{GHz}$ & $3,0 \mathrm{~mm}$ & $0,48 \mathrm{~mm}$ & 1,7 & 5,0 \\
\hline $200 \mathrm{GHz}$ & $1,5 \mathrm{~mm}$ & $0,24 \mathrm{~mm}$ & 3,3 & 10,0 \\
\hline $300 \mathrm{GHz}$ & $1,0 \mathrm{~mm}$ & $0,16 \mathrm{~mm}$ & 5,0 & 15,0 \\
\hline
\end{tabular}

A Tabela 3.7 apresenta os comprimentos de onda para 100, 200e $300 \mathrm{GHz}$ de frequências portadoras na distância do limite do campo próximo e o número de comprimento de onda em $5 \mathrm{~nm}$ e $15 \mathrm{~nm}$. Tendo em conta que o campo próximo é considerado insignificante após uma distância de três a dez comprimentos de onda

\subsubsection{Resposta da antena de baixa frequência variando a distância}

Como foi visto na seção 3.3.1, para a antena de baixa frequência, só se fez a análise da resposta, em função das frequências portadoras, para uma única frequência de modulação: $2 \mathrm{MHz}$; assim para a análise da resposta da antena em função da distância também usamos essa única frequência de modulação e também uma única frequência portadora: $100 \mathrm{GHz}$.

A Figura 3.12 apresenta a resposta da antena em função da distância, onde a variação da distância foi feita com passos $20 \mu \mathrm{m}$, com um total de 6000 passos, cobrindo assim uma distância de $12.0 \mathrm{~cm}$. O comportamento oscilatório da potência também pode ser observado da mesma forma como na Figura 3.7. 


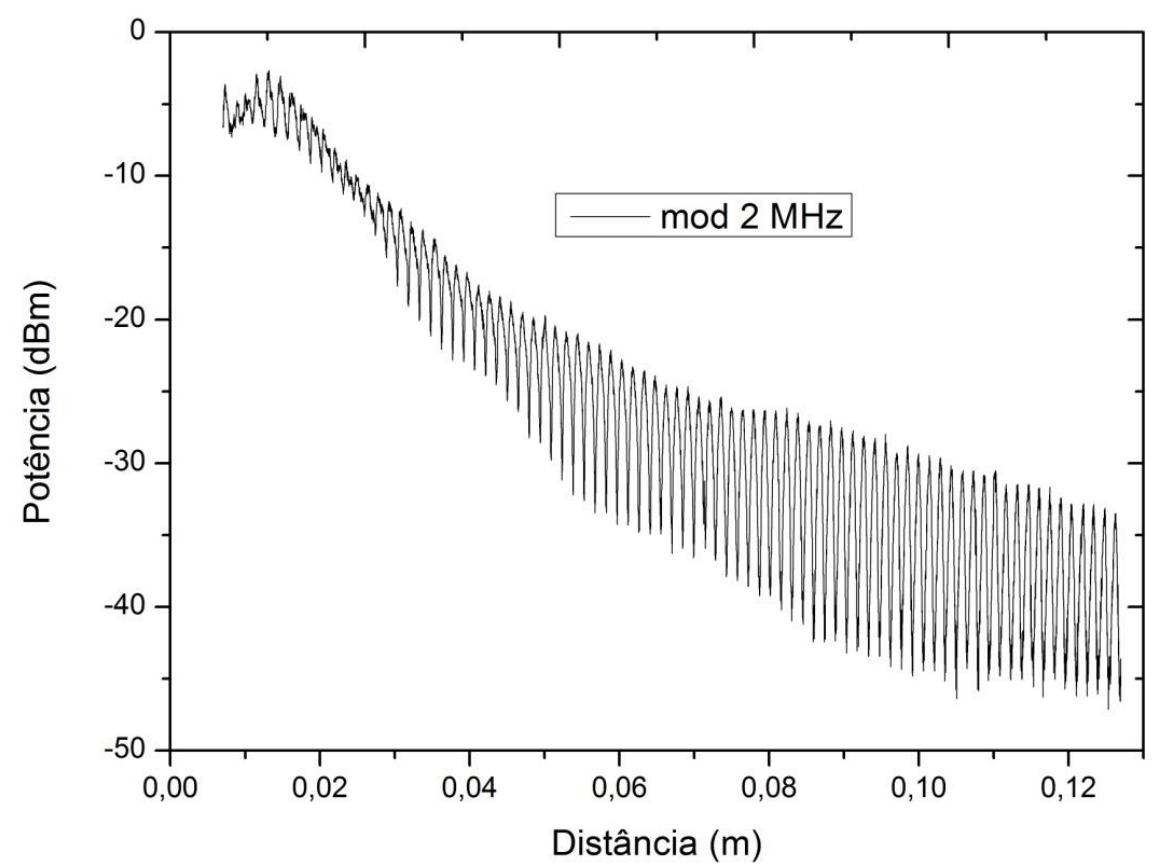

Figura 3.12: Resposta em potência da antena com relação à distância.

Considerando os dados da Figura 3.6 com a Figura 3.11 a melhor relação SNR está nos primeiros centímetros, $15.1 \mathrm{~mm}$ para a antena de alta frequência e $12.9 \mathrm{~mm}$ para a antena de baixa frequência. Podemos assim comparar graficamente a SNR das duas antenas para as suas melhores respostas; para antena da alta frequência a melhor resposta foi para uma modulação de $500 \mathrm{MHz}$ e para a antena de baixa frequência a melhor resposta foi para uma modulação de $2 \mathrm{MHz}$. Essa comparação é apresentada na Figura 3.13, para diferentes frequências portadoras. 


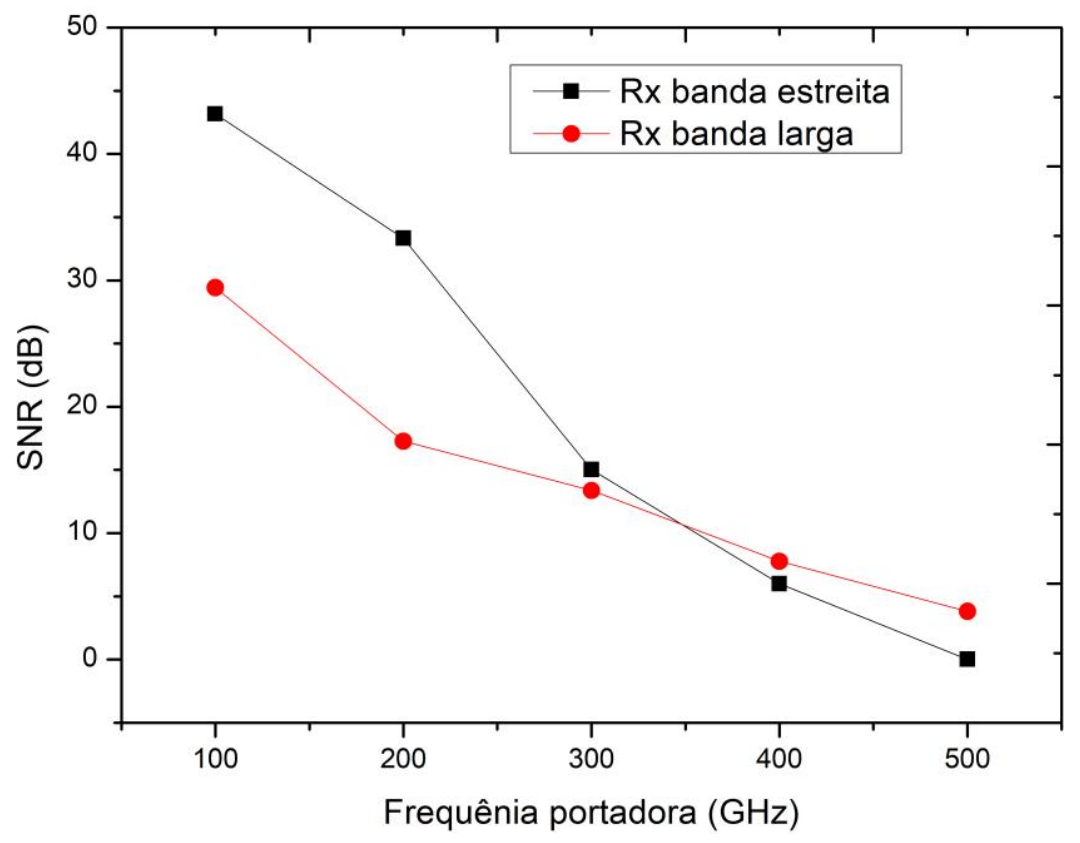

Figura 3.13: Comparação de SNR das duas antenas receptoras variando a frequência da portadora.

Pode-se observar na Figura 3.13 que a SNR da antena de baixa frequência é melhor à de alta frequência em aproximadamente $14 \mathrm{~dB}$ na frequência portadora de 100 $\mathrm{GHz}$ e em 16 dB na frequência portadora de $200 \mathrm{GHz}$. Essa diferença pode ser atribuída à potência de ruído equivalente (NEP: Noise-equivalent Power) das antenas, as quais são mostradas na Tabela 3.8, conjuntamente são mostradas outras características segundo o fabricante.

Tabela 3.8 Especificações entre as antenas de banda larga e a antena de banda estreita [57].

\begin{tabular}{|l|l|l|}
\hline Parâmetro & Antena de banda estreita & Antena de banda larga \\
\hline $\begin{array}{l}\text { Noise-equivalent } \\
\text { Power }\end{array}$ & $\begin{array}{l}7 \mathrm{pW} / \mathrm{sqrt}(\mathrm{Hz}) @ 100 \mathrm{Ghz}, \\
100 \mathrm{pW} / \mathrm{sqrt}(\mathrm{Hz}) @ 1 \mathrm{THz}\end{array}$ & $\begin{array}{l}70 \mathrm{pW} / \mathrm{sqrt}(\mathrm{Hz}) @ 100 \mathrm{Ghz}, \\
1000 \mathrm{pW} / \mathrm{sqrt}(\mathrm{Hz}) @ 1 \mathrm{THz}\end{array}$ \\
\hline Responsivity & $\begin{array}{l}25000 \mathrm{~V} / \mathrm{W} @ 100 \mathrm{GHz}, \\
2000 \mathrm{~V} / \mathrm{W} @ 1 \mathrm{THz},\end{array}$ & $\begin{array}{l}250 \mathrm{~V} / \mathrm{W} @ 100 \mathrm{GHz}, \\
20 \mathrm{~V} / \mathrm{W} @ 1 \mathrm{THz},\end{array}$ \\
\hline $\begin{array}{l}\text { Amplifier } \\
\text { bandwidth }\end{array}$ & $10 \mathrm{~Hz}-1 \mathrm{MHz}$ & $10 \mathrm{MHz}-4 \mathrm{GHz}$ \\
\hline
\end{tabular}


Pode-se observar na Figura 3.13 que a SNR da antena de baixa frequência é melhor à de alta frequência em aproximadamente $14 \mathrm{~dB}$ na frequência portadora de 100 $\mathrm{GHz}$ e em $16 \mathrm{~dB}$ na frequência portadora de $200 \mathrm{GHz}$. Essa diferença pode ser atribuída à potência de ruído equivalente (NEP: Noise-equivalent Power) das antenas, as quais são mostradas na Tabela 3.8, conjuntamente são mostradas outras características segundo o fabricante.

Para a transmissão de dados foi usado o padrão LTE (Long Term Evolution). A Figura 3.14 apresenta o espectro do sinal modulado com o modelo ETM 1.1 (EUTRAN Test Model). É importante ressaltar que esta modulação distribui a potência da portadora em múltiplas subportadoras dentro de uma banda de $1.4 \mathrm{MHz}$, assim, como mostrado na figura, o nível máximo da portadora, que foi de $-5 \mathrm{dBm}$ aproximadamente, foi para $-34 \mathrm{dBm}$. É por essa razão que a antena de baixa frequência possibilitou a transmissão dos dados o qual não teria sido possível com a antena de alta frequência já que a sua relação SNR não era suficiente.

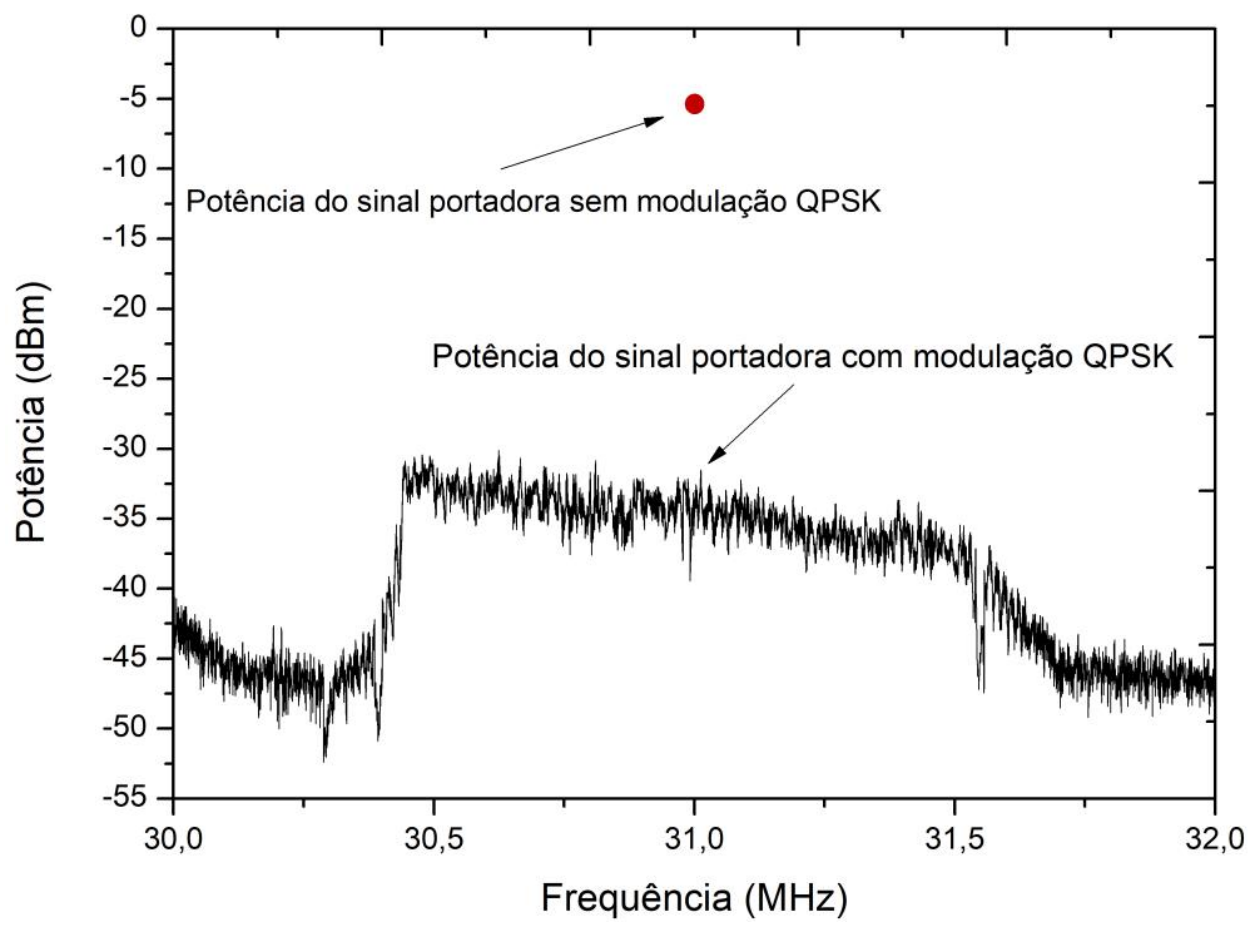

Figura 3.14: Sinal modulada e Sinal não modulada em relação à frequência.

Podemos observar também que, na Figura 3.14, a frequência central da portadora está em $31 \mathrm{MHz}$, sendo que o sinal modulador gerado pelo VSG tem a 
sua portadora em $2 \mathrm{MHz}$; mas, como sabemos, o VSA tem a sua frequência mínima de trabalho em $30 \mathrm{MHz}$ assim, depois da detecção e amplificação, o sinal detectado foi misturado com um sinal de $29 \mathrm{MHz}$, levando a frequência do sinal detectado até $31 \mathrm{MHz}$, já que a frequência mínima de trabalho do VSA, segundo a suas especificações, é de $30 \mathrm{MHz}$, obtendo assim o espectro da figura, o qual pode ser analisado pelo VSA.

$\mathrm{Na}$ figura também se mostra um comportamento inclinado no sinal obtido, isso é devido a que a largura de banda do amplificador da mesma antena de banda estreita trabalha na faixa de $10 \mathrm{~Hz}$ até $1 \mathrm{MHz}$, mas nosso experimento o VSG foi configurado com uma banda de 1,4 MHz para as subportadoras. 


\section{Resultados do experimento transmitindo informação}

Depois de ver os resultados das duas antenas e compará-las, comprovou-se que a segunda configuração, com a antena de baixa frequência é a melhor opção para conseguir transmitir dados na banda de EHF.

\subsection{Resposta do EVM variando a potência da antena Tx.}

Nos capítulos anteriores se realizaram estudos procurando a melhor forma de obter os dados com as melhores características, provando diferentes antenas, geradores, amplificadores, estabelecendo assim uma configuração ótima para transmitir ondas em EHF.

Ao conseguir os melhores resultados mediante a segunda configuração, realizaram-se provas de envio de informação.

Na Tabela 4.1, mostra os valores do EVM obtidos variando a potência óptica na antena transmissora mexendo o VOA 1 mostrado na Figura 3.10 para uma distância fixa de $5 \mathrm{~mm}$ e obter uma relação entre a potência que chega à antena e o EVM mostrado no VSA.

Tabela 4.1: Resultados do EVM variando a potência óptica da antena Tx

\begin{tabular}{|c|c|}
\hline PTx. $\mathrm{mW}$ & EVM \% \\
\hline 12 & 60 \\
\hline 13 & 55 \\
\hline 14 & 42 \\
\hline 15 & 36 \\
\hline 16 & 25 \\
\hline 17 & 21 \\
\hline 18 & 20 \\
\hline
\end{tabular}

\begin{tabular}{|c|c|}
\hline PTx.mW & EVM \% \\
\hline 19 & 18 \\
\hline 20 & 16 \\
\hline 21 & 15 \\
\hline 22 & 14 \\
\hline 23 & 13 \\
\hline 24 & 12 \\
\hline 25 & 11 \\
\hline
\end{tabular}

\begin{tabular}{|c|c|}
\hline PTx. mW & EVM \% \\
\hline 26 & 11 \\
\hline 27 & 10 \\
\hline 28 & 10 \\
\hline 29 & 10 \\
\hline 30 & 10 \\
\hline 31 & 10 \\
\hline 32 & 10 \\
\hline
\end{tabular}


A Figura 4.1, apresenta graficamente os resultados mostrados na Tabela 4.1.

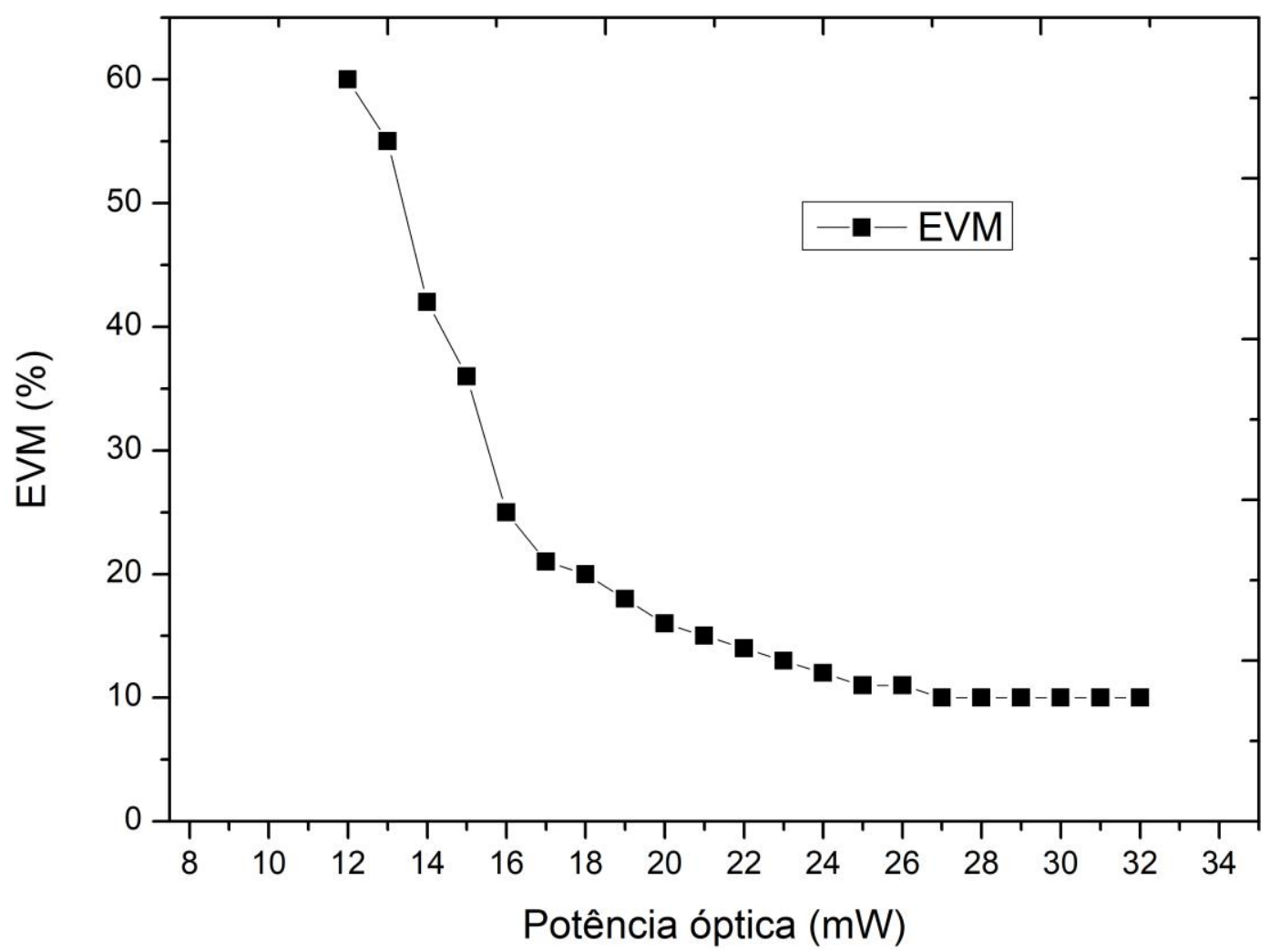

Figura 4.1: Variação do EVM em relação à potência óptica da antena Tx.

Lembrando que o padrão E-TM 1.1, considera só os valores com um EVM menor ao $17,5 \%$.

$\mathrm{Na}$ Tabela 4.1 observa-se que com uma potência de $20 \mathrm{~mW}$ na antena transmissora, o EVM é de 16\%, sendo um valor aceitável pelo padrão utilizado, mas, com uma potência de $30 \mathrm{~mW}$ chega até $10 \%$, sendo uma referência melhor para pegar mais dados com relação à distância.

Os dados obtidos na

Figura 4.2, apresenta a variação do EVM em função da distância. Cada ponto foram entre distâncias de $20 \mu \mathrm{m}$ entre, com um total de 1501 pontos com uma potência fixa de $31 \mathrm{~mW}$ na antena transmissora sem variar nenhum parâmetro, somente a distância. 
Fizeram-se várias provas de distância com os mesmos valores, com maior quantidade de pontos, mas depois de alcançar uma distância de aproximadamente $1.5 \mathrm{~cm}$, já excedia o mínimo valor do padrão E-TM 1.1.

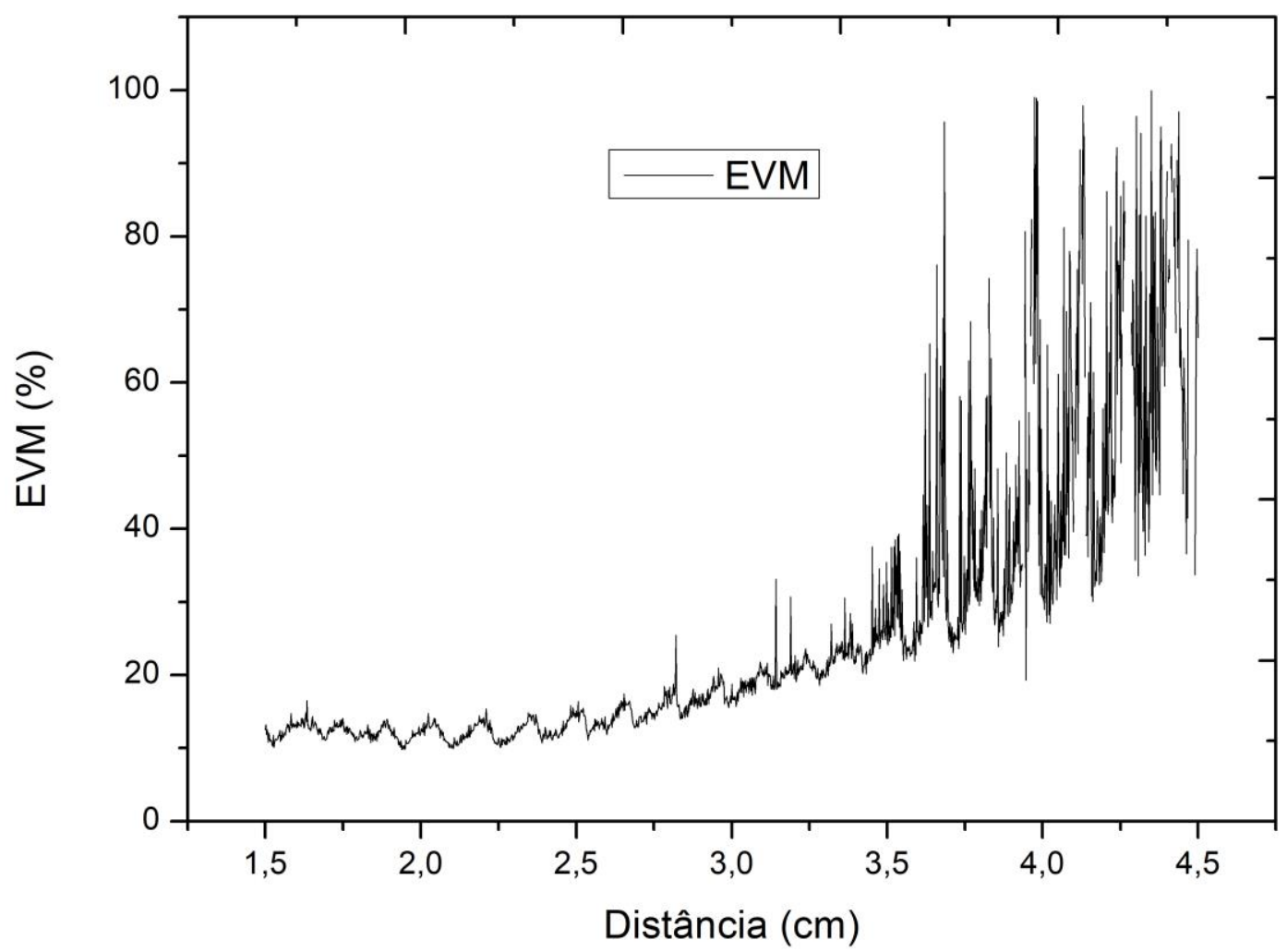

Figura 4.2: EVM com relação à distância.

Como foi explicado anteriormente, o EVM é a diferença entre os símbolos recebidos pela antena e os símbolos ideais, que neste caso o padrão E-TM 1.1 está enviando, então, se as diferenças vão aumentando, a porcentagem de não coincidência entre os símbolos vai ser maior, é por isso que em modulações de QPSK só é aceitável EVM até 17,5\%.

No EVM podem-se observar oscilações como na Figura 3.12. Estas oscilações são ocasionadas pelos feixes refletidos entre as duas antenas (Tx e Rx). Quando as duas antenas vão-se afastando, a interferência produzida na cavidade delas vai mudando. Então, pode-se assumir que, o EVM tem relação direta com a potência transmitida. 
Na figura 4.3 se compara a potência obtida na Figura 3.12 com o EVM da Figura 4.2:

$\mathrm{Na}$ Figura 4.3 se tem valores maiores a $50 \%$, o que indica que, nessa distância, os símbolos recebidos, não tem quase coincidência com os símbolos ideais, e no caso dos valores a 100\%, a não coincidência entre os símbolos é total.

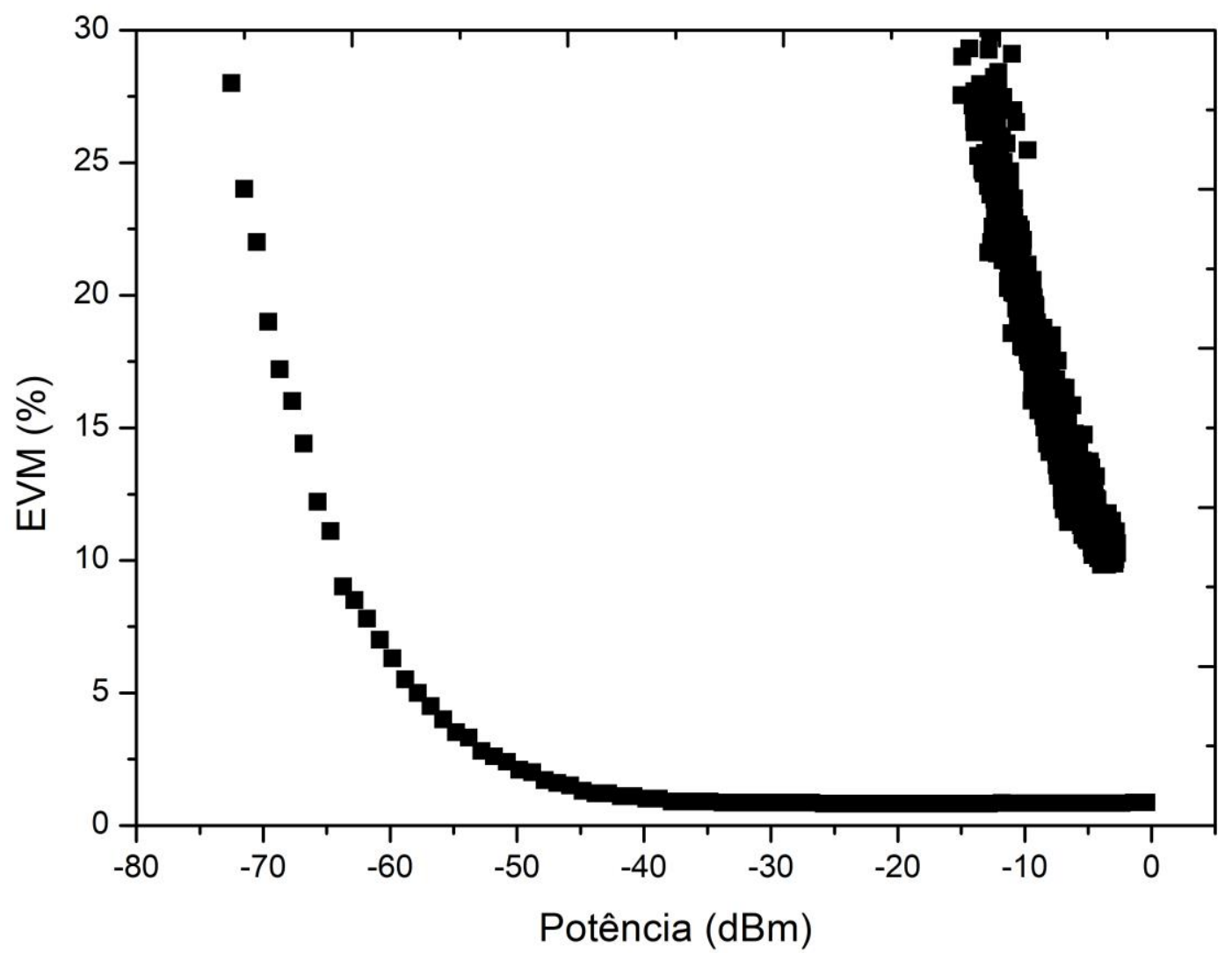

Figura 4.3: resposta do EVM com relação aos níveis das potências obtidas na Figura 3.12

No resultado obtido se mostra o EVM com relação a potência da portadora em $31 \mathrm{MHz}$ obtida usando a antena Schottky de banda estreita sem o sinal modulada em QPSK e outro sinal onde cada ponto representa um porcentagem do EVM back to back. Para um sinal com modulação QPSK enviada diretamente do VSG para o VSA usando uma portadora de $31 \mathrm{MHz}$, Pode-se observar que a curva do sinal EHF 
é deslocada $60 \mathrm{~dB}$ para a direita, onde pode-se apreciar uma atenuação do sinal devido ao ruído da antena, do amplificador e do misturador.

Neste trabalho numa distância de 1,5 cm alcançou-se o mínimo valor do EVM para o padrão E-TM 1.1, isto significa que o valor da potência alcançada nessa distância é o mínimo valor aceitável para o padrão, que neste caso seria uma potência de $-8 \mathrm{dBm}$ aproximadamente como é mostrado na Figura 4.4.

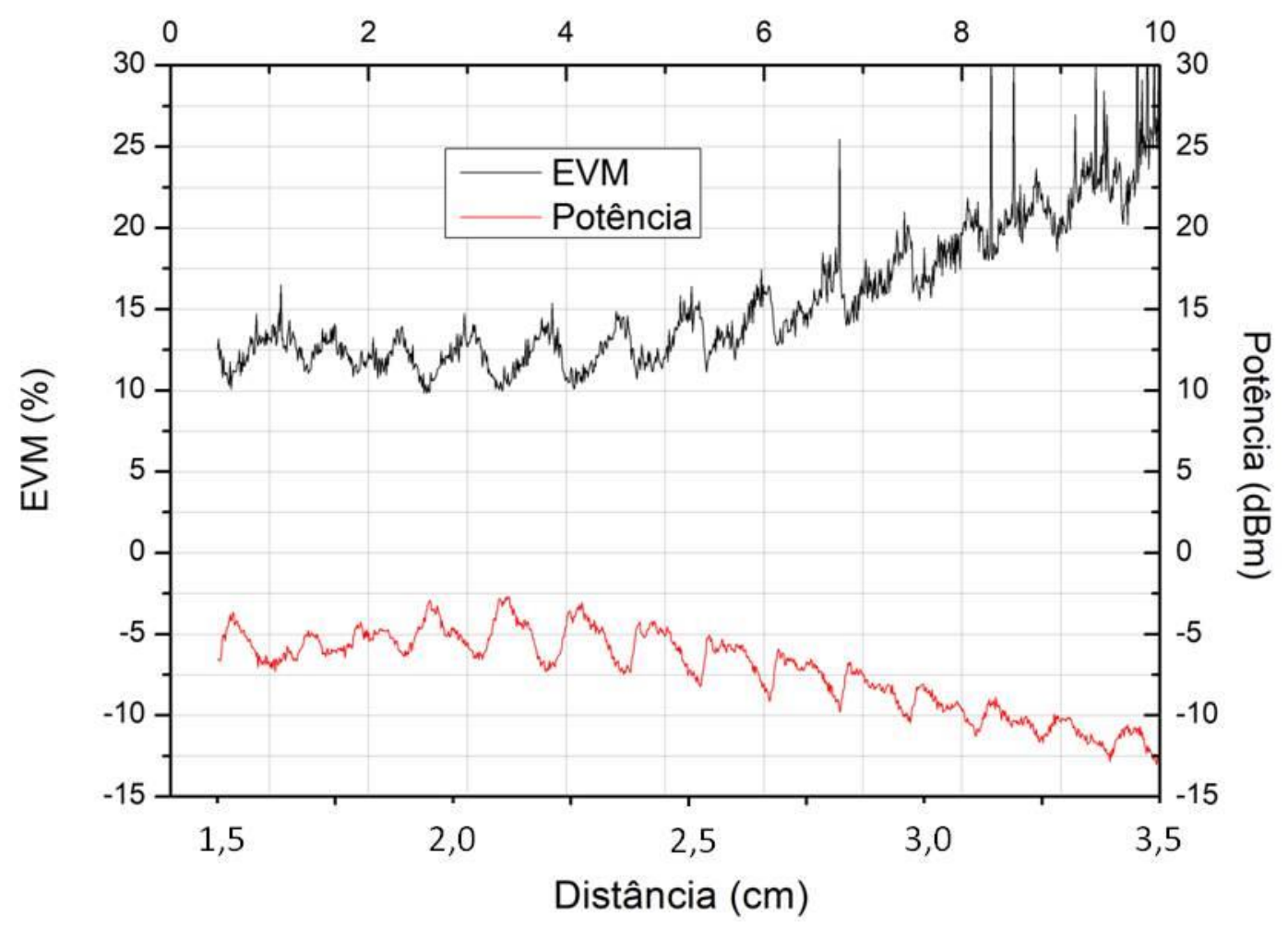

Figura 4.4: EVM e Potência de recepção com relação à distância.

Os picos que mostra a potência de recepção correspondem com as medidas do menor valor do EVM.

Ao mexer os parâmetros do experimento como: a fonte da antena (aumentando a potência), mudando o BIAS e a potência do amplificador e colocando a antena receptora a uma distância de $2,1 \mathrm{~cm}$, conseguiu-se um valor de EVM de $15 \%$, dando assim um valor aceitável para o padrão utilizado. 
Tendo em conta o último valor alcançado numa distância de $2,1 \mathrm{~cm}$, pode-se assumir que é possível melhorar o sinal em diferentes distâncias com valores aceitável de EVM, mas é necessário mexer os valores dos equipamentos para cada distância. 


\section{Conclusões}

Neste trabalho se apresenta duas configurações para gerar frequências na banda milimétrica (EHF) mediante a técnica de batimento de dois lasers em diferentes frequências, onde um dos lasers foi modulado em AM com um único tom de frequência para a primeira configuração, e na segunda configuração foi modulado em QPSK com o objetivo de poder transmitir e detectar informação usando faixas de frequências a partir de $100 \mathrm{GHz}$ ou mais.

Ao trabalhar com a antena de alta frequência na primeira configuração com uma modulação AM, detectaram-se sinais na faixa de frequência de portadora de $100 \mathrm{GHz}$ até $400 \mathrm{GHz}$ com modulações de 0,5 até $4 \mathrm{GHz}$, obtendo as maiores potências sobre o ruído na frequência de 100, 200 e $300 \mathrm{GHz}$. Seguidamente, foise aumentando a distâncias entre as duas antenas (Tx e Rx) nestas 3 frequências para observar o comportamento do sinal nas diferentes frequências de modulação, dando como resultado que na frequência de $100 \mathrm{GHz}$ com uma modulação de 0,5 $\mathrm{GHz}$ se tem sinal até uma distância de $11 \mathrm{~cm}$, enquanto nas outras frequências, o sinal vai-se misturando com o ruído depois do que antena Rx vai-se afastando da antena Tx.

Depois de determinar que, na primeira configuração, a melhor opção para o envio de informação é na frequência de $100 \mathrm{GHz}$ com uma modulação de $0,5 \mathrm{GHz}$, foi realizado uma segunda configuração com outra antena de baixa frequência caracterizada da mesma forma em frequências de $100 \mathrm{GHz}$ até $500 \mathrm{GHz}$, mas com uma modulação QPSK com uma frequência de $2 \mathrm{MHz}$, obtendo o melhor resultado na frequência de $100 \mathrm{GHz}$ com uma potência de pouco mais de $40 \mathrm{~dB}$ sobre o ruído numa distância de $6 \mathrm{~mm}$ aproximados, demonstrando assim, que a antena de baixa frequência tem melhor resposta em $13 \mathrm{~dB}$ de potência aproximadamente que a outra antena de altas frequências. 
Ao fazer a modulação em QPSK de um sinal com o padrão E-TM 1.1, observou-se que a potência que o VSA mostrava no analisador de espectro diminuía em $30 \mathrm{~dB}$, e isso fazia que a potência da antena de alta frequência ficara dentro dos níveis do ruído, sem poder detectar nenhum símbolo no EVM. Mas com a antena de banda estreita conseguiu-se um EVM de 10 \%uma distância de 6 mm aproximadamente. Dando como resultado uma relação entre a potência do sinal com o EVM que se encontro (enquanto maior a potência do sinal, melhor o EVM).

Finalmente se fez uma última medida na distância de $2,1 \mathrm{~cm}$, com um resultado aceitável de 15\% de EVM, encontrando-se este valor dentro da faixa do padrão que foi utilizado para a modulação QPSK, mas foi obtida mexendo os valores dos equipamentos para ter uma melhora do sinal (enquanto as demais medidas foram obtidas com valores fixos de amplitude no gerador, BIAS da antena e do modulador, etc.), fazendo possível obter melhores dados em distâncias mais longas entre as antenas.

É bom mencionar que parte dos resultados obtidos neste trabalho serão apresentados na International Microwave and Optoelectronics Conference (IMOC2017) [64]. 


\section{Referências bibliográficas}

[1] M. A. B. Saucedo, "Espectroscopia THz en el dominio del tiempo."

[2] K.-C. Huang and Z. Wang, Millimeter wave communication systems. Hoboken, N.J: Wiley, 2011.

[3] P. H. Siegel, “Terahertz Technology in Biology and Medicine," IEEE Trans. Microw. Theory Tech., vol. 52, no. 10, pp. 2438-2447, Oct. 2004.

[4] L. Jiusheng, "Optical parameters of vegetable oil studied by terahertz timedomain spectroscopy,” Appl. Spectrosc., vol. 64, no. 2, pp. 231-234, 2010.

[5] C. Kulesa, "Terahertz Spectroscopy for Astronomy: From Comets to Cosmology," IEEE Trans. Terahertz Sci. Technol., vol. 1, no. 1, pp. 232-240, Sep. 2011.

[6] F. Xin, H. Su, and Y. Xiao, "Terahertz imaging system for remote sensing and security applications," in Antennas and Propagation (APCAP), 2014 3rd AsiaPacific Conference on, 2014, pp. 1335-1338.

[7] T. Nagatsuma, K. Kato, and J. Hesler, "Enabling Technologies for Real-time 50Gbit/s Wireless Transmission at $300 \mathrm{GHz}, " 2015$, pp. 1-5.

[8] G. Ducournau et al., "32 Gbit/s QPSK transmission at $385 \mathrm{GHz}$ using coherent fibre-optic technologies and $\mathrm{THz}$ double heterodyne detection," Electron. Lett., vol. 51, no. 12, pp. 915-917, 2015.

[9] T. Nagatsuma et al., "Real-time 100-Gbit/s QPSK transmission using photonicsbased 300-GHz-band wireless link," in Microwave Photonics (MWP), 2016 IEEE International Topical Meeting on, 2016, pp. 27-30.

[10]F. E. Sanjuan, “Generación, detección y procesamiento de señales electromagnéticas en la banda de Terahertz .pdf," Ph.D. Thesis, Universidad Nacional de La Plata, 2014.

[11] M. J. Weber, Handbook Of Laser Wavelengths. University of California: CRC Press LLC, 1999.

[12] Y.-S. Lee, Principles of Terahertz Science and Technology. Boston, MA: Springer US, 2009. 
[13] O. D. Dubon et al., “TERAHERTZ EMISSION FROM p-TYPE GERMANIUM LASERS DOPED WITH NOVEL ACCEPTORS ',” in Eighth International Symposium on Space Terahertz Technology, 1997, vol. 1, p. 423.

[14] M. Razeghi, S. Slivken, Y. Bai, and S. Darvish, "The Quantum Cascade LASER: A Versatile and Powerful Tool,” OPN, no. July/August, pp. 42-47, 2008.

[15] L. Hou, H. Park, and X. C. Zhang, “Terahertz Wave Imaging System Based on Glow Discharge Detector," IEEE J. Sel. Top. Quantum Electron., vol. 17, no. 1, pp. 177-182, Jan. 2011.

[16] “The World Wide Web Virtual Library: Free Electron Laser.” [Online]. Available: http://sbfel3.ucsb.edu/www/vl_fel.html. [Accessed: 02-Nov-2016].

[17] "Encyclopedia of Laser Physics and Technology - free electron lasers, FEL." [Online]. Available: https://www.rp-photonics.com/free_electron_lasers.html. [Accessed: 03-Nov-2016].

[18] M. G. Krishna, S. D. Kshirsagar, and S. P. Tewari, Terahertz emitters, detectors and sensors: Current status and future prospects. INTECH Open Access Publisher, 2012.

[19] W. R. Huang et al., "Highly efficient terahertz pulse generation by optical rectification in stoichiometric and cryo-cooled congruent lithium niobate," $J$. Mod. Opt., vol. 62, no. 18, pp. 1486-1493, Oct. 2015.

[20] "generation of THz pulses by optical rectification - cavalleri research group." [Online]. Available: http://mpsd-cmd.cfel.de/research-met-thz-optrect.html. [Accessed: 17-Nov-2016].

[21] H. A. Padovani Guimarães de Camargo and F. C. da Cruz, "Apoio ao Desenvolvimento de um Espectrômetro de Pulsos de THZ e Aplicações," presented at the XXI Congresso de Iniciação Científica da Unicamp-PIBIC, Unicamp (GMU), 2013.

[22] “THz Basics - Terahertz Laboratories.” [Online]. Available: http://www.thz.phys.soton.ac.uk/thz-basics. [Accessed: 21-Nov-2016].

[23] Q. Wu and X.-C. Zhang, "Free-space electro-optic sampling of terahertz beams," Appl. Phys. Lett., vol. 67, no. 24, p. 3523, 1995.

[24] M. D. Thomson, V. Blank, and H. G. Roskos, "Recovery of ultra-broadband terahertz pulses from sum-frequency spectrograms using a generalized deconvolution method," EPJ Web Conf., vol. 41, p. 09011, 2013. 
[25] M. Baillergeau et al., "Diffraction-limited ultrabroadband terahertz spectroscopy," Sci. Rep., vol. 6, p. 24811, May 2016.

[26] C. W. Berry, N. Wang, M. R. Hashemi, M. Unlu, and M. Jarrahi, "Significant performance enhancement in photoconductive terahertz optoelectronics by incorporating plasmonic contact electrodes," Nat. Commun., vol. 4, p. 1622, Mar. 2013.

[27] M. O. Reese, "Superconducting hot electron bolometers for terahertz sensing," Citeseer, 2006.

[28] "Pyroelectric Detectors: Materials, Applications, and Working Principle." [Online]. Available: http://www.lasercomponents.com/de-en/news/pyroelectricdetectors-materials-applications-and-working-principle/. [Accessed: 22-Nov2016].

[29] “thermocouple." [Online]. Available: http://www.columbia.edu/itc/chemistry/ARCHIVE/chemc1500TL/experiments/session3/thermocouple/thermocouple.html. [Accessed: 22Nov-2016].

[30] K. Yamashita, A. Murata, and M. Okuyama, "Miniaturized infrared sensor using silicon diaphragm based on Golay cell," Sens. Actuators Phys., vol. 66, no. 1, pp. 29-32, 1998.

[31] Sampath Kumar, "Thermal detectors of ir," 08:22:17 UTC.

[32] G. J. Fertig, "Evaluation of MOSFETs for Terahertz Detector Arrays,” 2014.

[33] K. Zeljami et al., "Caracterización de diodos Schottky para banda W," 2012.

[34] A. Rogalski and F. Sizov, "Terahertz detectors and focal plane arrays," OptoElectron. Rev., vol. 19, no. 3, Jan. 2011.

[35] C. M. da Costa, W. M. S. Santos, and A. M. Luiz, "Supercondutores: aplicações das junções Josephson na eletrônica,” 2004.

[36] G. Q. de Freitas, “Construção de uma junção Josephson em filmes finos supercondutores do sistema $\mathrm{Bi} 1$. $8 \mathrm{~Pb} 0.4 \mathrm{Sr} 2 \mathrm{CaCu} 2 \mathrm{Ox}$ tratados termicamente em um forno microondas doméstico,” 2012.

[37] Y. Zhang, K. Shibata, N. Nagai, C. Ndebeka-Bandou, G. Bastard, and K. Hirakawa, "Gate-controlled terahertz single electron photovoltaic effect in selfassembled InAs quantum dots," Appl. Phys. Lett., vol. 107, no. 10, p. 103103 , Sep. 2015. 
[38] J. Olitsky, K. Hirakawa, K. Shibata, and Y. Zhang, "InAs quantum dot single electron transistors.pdf." 2012.

[39] H. Liu, J. Yu, P. G. Huggard, and B. Alderman, "Measurements of Schottkydiode based THz video detectors," Terahertz Sci. Technol., vol. 4, no. 3, pp. 104$108,2011$.

[40] M. G. Albarracin Polo, “Técnicas de modulação em EHF," Master’s thesis, PUCRio, Rio de Janeiro, 2016.

[41] Da. Saeedkia, Ed., Handbook of terahertz technology for imaging, sensing and communictions. Cambridge, UK; Philadelphia, PA: Woodhead Publishing, 2013.

[42] C. Kitano and J. E. B. Oliveira, "Projeto de Moduladores Eletroópticos Faixa Larga Utilizando Tecnologia de Óptica Integrada,” Rev. Telecomunicações, vol. 2, no. 2, pp. 5-16.

[43] A. P. Togneri, “Analise de Sistemas de Multiplexacao porSubportadora," Universidade Federal do Espírito Santo, 2005.

[44] "MODULAÇÃO.” [Online]. Available:

http://www.gta.ufrj.br/grad/04_2/Modulacao/. [Accessed: 14-Feb-2017].

[45] R. Machado, “Telefonia Celular Aula 16 - Modulação digital para comunicações móveis." Universidade Federal de Santa Maria Departamento de Eletrônica e Computação Telefonia Celular, Aug-2011.

[46] M. Hudlicka, C. Lundstrom, D. A. Humphreys, and I. Fatadin, "BER estimation from EVM for QPSK and 16-QAM coherent optical systems,” 2016, pp. 1-3.

[47] M. D. McKinley, K. A. Remley, M. Myslinski, J. S. Kenney, D. Schreurs, and B. Nauwelaers, "EVM calculation for broadband modulated signals," in 64th ARFTG Conf. Dig, 2004, pp. 45-52.

[48] National Instruments, “Introduction to LTE Device Testing.” National Instruments.

[49] C. Ibarz, J. Carlos, A. Röck, A. Caccia, A. Funk, and L. Rizzo, "ETSI EN 319132 Part 1 (Draft): 'Electronic Signatures and Infrastructures (ESI); XML Advanced Electronic Signatures (XAdES); Part 1 Core Specification’ v0.0.4.” 30-Sep-2013. [50] J. Veloso and G. Madruga, “3-Introducao_ao_Fabry-red.pdf.” .

[51] Wavelength References, "Clarity ${ }^{\mathrm{TM}}$ Precision Frequency Standard Narrow Line Semiconductor Laser." .

[52] Newport, "Velocity ${ }^{\mathrm{TM}} 6700$ Widely Tunable Lasers." Nov-2015.

[53] Anritsu Corporation, "MS9710C Operation Manual.pdf.” 26-Dec-2008. 
[54] Covega, “Covega Products \& Services Catalog 2008.” 2008.

[55] “RF/Microwave Signal Generator MG3690B Series- Anritsu America.” [Online]. Available: http://www.anritsu.com/en-us/test-measurement/products/mg3690bseries. [Accessed: 20-Apr-2017].

[56] Anritsu Corporation, “Anritsu MS2702A Spectrum Analyzer $100 \mathrm{~Hz}$ to 24.5 GHz," Advanced Test Equipment Rentals. [Online]. Available: https://www.atecorp.com/products/anritsu/ms2702a. [Accessed: 20-Apr-2017].

[57] "Schottky Receivers," TOPTICA Photonics AG, 21-Mar-2017. [Online]. Available: http://www.toptica.com/products/terahertzsystems/accessories/schottky-receivers/. [Accessed: 25-Apr-2017].

[58] M. Casper, "Radar Testbed Characterization for Evaluation of Modulated Scatterer Concepts," Master's thesis, University of Kansas, 2010.

[59] Anritsu Corporation, "Vector Signal Generator MG3710A- Anritsu America." [Online]. Available: https://www.anritsu.com/en-US/testmeasurement/products/mg3710a. [Accessed: 20-Apr-2017].

[60] Anritsu Corporation, "Signal Analyzers MS2692A- Anritsu America.” [Online]. Available: https://www.anritsu.com/en-us/test-measurement/products/ms2692a. [Accessed: 20-Apr-2017].

[61] Mini-Circuits, “ZFM-2H-S+ Coaxial Frequency Mixer.”.

[62] “81150A Gerador de pulsos, padrões, formas de onda arbitrárias e ruídos | Keysight (formerly Agilent's Electronic Measurement).” [Online]. Available: http://www.keysight.com/pt/pd-1287544-pn-81150A/pulse-function-arbitrarynoise-generator?cc $=B R \& l c=$ por $\& 1$ srch $=$ true $\&$ searchT $=81150$ A. [Accessed: 15 Feb-2017].

[63] “L3 Narda-MITEQ — Narda-MITEQ Model AU-1442.” [Online]. Available: https://miteq.com/viewmodel.php?model=AU-1442. [Accessed: 15-Feb-2017].

[64] A. Alvarez Arellano, A. H. Cordes, L. E. Ynoquio Herrera, and J. P. von der Weid, "Data transmission in the EHF band with QPSK modulation," presented at the IMOC 2017, to be published. 